NBER WORKING PAPER SERIES

\title{
MEASURES OF PARTICIPATION IN GLOBAL VALUE CHAINS AND GLOBAL BUSINESS CYCLES
}

\author{
Zhi Wang \\ Shang-Jin Wei \\ Xinding Yu \\ Kunfu Zhu \\ Working Paper 23222 \\ http://www.nber.org/papers/w23222 \\ NATIONAL BUREAU OF ECONOMIC RESEARCH \\ 1050 Massachusetts Avenue \\ Cambridge, MA 02138 \\ March 2017
}

The views expressed herein are those of the authors and do not necessarily reflect the views of the National Bureau of Economic Research.

NBER working papers are circulated for discussion and comment purposes. They have not been peer-reviewed or been subject to the review by the NBER Board of Directors that accompanies official NBER publications.

(C) 2017 by Zhi Wang, Shang-Jin Wei, Xinding Yu, and Kunfu Zhu. All rights reserved. Short sections of text, not to exceed two paragraphs, may be quoted without explicit permission provided that full credit, including ( $)$ notice, is given to the source. 
Measures of Participation in Global Value Chains and Global Business Cycles

Zhi Wang, Shang-Jin Wei, Xinding Yu, and Kunfu Zhu

NBER Working Paper No. 23222

March 2017

JEL No. F10

\begin{abstract}
$\underline{\text { ABSTRACT }}$
This paper makes two methodological contributions. First, it proposes a framework to decompose total production activities at the country, sector, or country-sector level, to different types, depending on whether they are for pure domestic demand, traditional international trade, simple GVC activities, and complex GVC activities. Second, it proposes a pair of GVC participation indices that improves upon the measures in the existing literature. We apply this decomposition framework to a Global Input-Output Database (WIOD) that cover 44 countries and 56 industries from 2000 to2014 to uncover evolving compositions of different production activities. We also show that complex GVC activities co-move with global GDP growth more strongly than other types of production activities.

Zhi Wang

Schar School of Policy and Government

George Mason Universty

3351 Fairfax Drive, MS 3B1,

Alington, VA 22201

zwang36@gmu.edu

Shang-Jin Wei

Graduate School of Business

Columbia University

Uris Hall 619

3022 Broadway

New York, NY 10027-6902

and NBER

shangjin.wei@ columbia.edu

Xinding Yu

School of International Trade and Economics

University of International Business and Economics Beijing 100029, CHINA

yuxd@uibe.edu.cn

Kunfu Zhu

University of International Business and Economics Beijing 100029, CHINA

zhukunfu@163.com
\end{abstract}




\section{Introduction}

This paper aims to provide a methodology to decompose production activities at the country, sector, or country-sector level to different types depending on whether they are for domestic demand without involving trade, "traditional" trade (without involving trade in intermediate goods), simple global value chain (GVC) activities, or complex GVC activities. It also aims to propose a new pair of GVC participation indices that have better properties than the existing measures in the literature.

As GVC intermediate inputs that cross national borders, the first major issue to be resolved in GVC measurement is missing information on a division between final and intermediate usages in customs trade statistics. Since traded products are classified by customs product codes (such as the 10-digit Harmonized Tariff Schedule (HS) in the US), and owing to heterogeneity even within 10-digit HS product groups, properly identifying their final usage is not an easy task. Furthermore, supply-chain trade or cross-border production-sharing measures in the literature, such as "vertical specialization" (VS) proposed by Hummels et al. (2001) or "import to produce" (I2P) and "import to export" (I2E) proposed by Baldwin and Lopez (2013), are recursive concepts with pervasive double counting.

To overcome these difficulties, "factor content" or "value-added" trade, has emerged as the primary measures of cross-border production-sharing activities. As production factors such as land, labor, or capital are already measured, they are relatively easy to classify. Therefore, we can classify production activities based on factor content embodied in various products according to a uniform standard, which makes analytical work tractable.

In this paper, we propose a production activity decomposition framework that is consistent with the System of National Accounts standard (SNA), classifying these embedded factor content into GVC and non-GVC activities based on whether they cross national borders for production or not. Value-added creation is only classified as GVC activities when embodied factor content crosses national border for production purposes. Domestic input-output coefficient matrix and import input-output coefficient matrix in an 
inter-country input-output (ICIO) table are used to distinguish between domestic and foreign factor content in various production activities.

We propose two ways to decompose production activities into different types, corresponding to a producer's perspective (based on forward industrial linkages) and a user's perspective (based on backward industrial linkages). Following these decomposition formulas, we propose a pair of GVC participation indices that we show have more desirable properties than the existing measures in the literature.

The rest of the paper is organized as follows: Section 2 describes how GVC and Non-GVC activities are classified in our accounting framework and defines the new GVC participation indices. Section 3 applies the framework and indices to a newly updated global input-output database that covers 44 countries and 56 industries from 2000 to 2014 (Timmer, et al., 2016), and illustrates the advantages of our methods relative to the ones in the literature. Section 4 documents evolving composition patterns of different types of production activities and their co-movement with global output growth. Finally, Section 5 concludes.

\section{Indexes for Participation in Global Value Chain Participations}

\subsection{Accounting basics of production activity}

Without loss generality, let us consider a world economy with $\mathrm{G}$ countries and $\mathrm{N}$ sectors. Its economic structure is represented by the following Inter-Country InputOutput (ICIO) model in Table 1: 
Table 1 General Inter-Country Input-Output table

\begin{tabular}{|c|c|c|c|c|c|c|c|c|c|c|}
\hline \multirow{2}{*}{\multicolumn{2}{|c|}{ Inputs }} & \multicolumn{4}{|c|}{ Intermediate Use } & \multicolumn{4}{|c|}{ Final Demand } & \multirow{3}{*}{$\begin{array}{c}\begin{array}{c}\text { Total } \\
\text { Output }\end{array} \\
X^{1}\end{array}$} \\
\hline & & \multirow{2}{*}{$\frac{1}{Z^{11}}$} & \multirow{2}{*}{$\frac{2}{Z^{12}}$} & \multirow{2}{*}{$\begin{array}{l}\cdots \\
\cdots\end{array}$} & \multirow{2}{*}{$\frac{\mathrm{G}}{Z^{1 g}}$} & \multirow{2}{*}{$\frac{1}{Y^{11}}$} & \multirow{2}{*}{$\frac{2}{Y^{12}}$} & \multirow{2}{*}{$\cdots$} & \multirow{2}{*}{$\frac{\mathrm{G}}{Y^{1 g}}$} & \\
\hline \multirow{4}{*}{$\begin{array}{l}\text { Intermediate } \\
\text { Inputs }\end{array}$} & 1 & & & & & & & & & \\
\hline & 2 & $Z^{21}$ & $Z^{22}$ & $\cdots$ & $Z^{2 g}$ & $Y^{21}$ & $Y^{22}$ & $\cdots$ & $Y^{2 g}$ & $X^{2}$ \\
\hline & $\vdots$ & $\vdots$ & $\vdots$ & $\because$ & $\vdots$ & $\vdots$ & $\vdots$ & $\because$ & $\vdots$ & $\vdots$ \\
\hline & $\mathrm{G}$ & $Z^{g 1}$ & $Z^{g 2}$ & .. & $Z^{g g}$ & $Y^{g 1}$ & $Y^{g 2}$ & $\cdots$ & $Y^{g g}$ & $X^{g}$ \\
\hline \multicolumn{2}{|c|}{ Value-added } & $V a^{1}$ & $V a^{2}$ & $\cdots$ & $V a^{g}$ & & & & & \\
\hline \multicolumn{2}{|c|}{ Total input } & $\left(X^{1}\right)^{\prime}$ & $\left(X^{2}\right)^{\prime}$ & $\cdots$ & $\left(X^{g}\right)^{\prime}$ & & & & & \\
\hline
\end{tabular}

where $Z^{s r}$ is an $N \times N$ matrix of intermediate input flows that are produced in country $s$ and used in country $r ; Y^{s r}$ is an $N \times 1$ vector giving final products produced in country $s$ and consumed in country $r ; X^{s}$ is also an $N \times 1$ vector giving gross outputs in country $s$; and $V A^{s}$ denotes a $1 \times N$ vector of direct value added in country $s$. In this ICIO model, the input coefficient matrix can be defined as $A=Z \hat{X}^{-1}$, where $\hat{X}$ denotes a diagonal matrix with the output vector $X$ in its diagonal. The value added coefficient vector can be defined as $V=V a \hat{X}^{-1}$. Gross outputs $\mathrm{X}$ can be split into intermediate and final products, $A X+Y=$ $X$. Rearranging terms, we can reach the classical Leontief (1936) equation, $X=B Y$, where $B=(I-A)^{-1}$ is the well-known (global) Leontief inverse matrix.

The gross output production and use balance, or the row balance condition of the ICIO table in Table 1 can be written as:

$$
X=A X+Y=A^{D} X+Y^{D}+A^{F} X+Y^{F}=A^{D} X+Y^{D}+E
$$

Where $A^{D}=\left[\begin{array}{cccc}A^{11} & 0 & \cdots & 0 \\ 0 & A^{22} & \cdots & 0 \\ \vdots & \vdots & \ddots & \vdots \\ 0 & 0 & \cdots & A^{g g}\end{array}\right]$ is a $\mathrm{GN} \times \mathrm{GN}$ diagonal block matrix of domestic input coefficient, $A^{F}$ is a $\mathrm{GN} \times \mathrm{GN}$ off-diagonal block matrix of imported input coefficient, $A^{F}=A-A^{D}, Y=\left[\begin{array}{llll}\sum_{r}^{G} Y^{1 r} & \sum_{r}^{G} Y^{2 r} & \cdots & \sum_{r}^{G} Y^{g r}\end{array}\right]^{\prime}$ is a $\mathrm{GN} \times 1$ vector of final goods and services production, $Y^{D}=\left[\begin{array}{llll}Y^{11} & Y^{22} & \ldots & Y^{g g}\end{array}\right]^{\prime}$ is a $\mathrm{GN} \times 1$ vector of final goods and service production for domestic consumption, $Y^{F}=Y-Y^{D}$ is a $\mathrm{GN} \times 1$ 
vector of final products exports, $E=\left[\begin{array}{llll}\sum_{r \neq 1}^{G} E^{1 r} & \sum_{r \neq 2}^{G} E^{2 r} & \cdots & \sum_{r \neq g}^{G} E^{g r}\end{array}\right]^{\prime}$ is a $\mathrm{GN} \times 1$ vector of gross exports, 'denotes transpose operation.

Rearranging equation (1) yields

$$
\begin{aligned}
& X=\left(I-A^{D}\right)^{-1} Y^{D}+\left(I-A^{D}\right)^{-1} E=L Y^{D}+L E \\
& =L Y^{D}+L Y^{F}+L A^{F} X
\end{aligned}
$$

where $\mathrm{L}=\left(I-A^{\mathrm{D}}\right)^{-1}$ is defined as local Leontief inverse, a GN by GN diagonal block matrix. Pre-multiplying with the GN by GN diagonal matrix $\widehat{V}$ of direct value-added coefficients, replacing $\mathrm{X}$ as $\mathrm{BY}$, and further converting the 3 final goods and service production vectors $Y^{D}, Y^{F}$ and $Y$ into GN by GN diagonal matrix $\hat{Y}, \hat{Y}^{D}$ and $\hat{Y}^{F}$, we can obtain the decomposition of value added and final products production simultaneously as follows:

$$
\begin{aligned}
\hat{V} B \hat{Y} & =\hat{V} L \hat{Y}^{D}+\hat{V} L \hat{Y}^{F}+\hat{V} L A^{F} B \hat{Y} \\
& =\hat{V} L \hat{Y}^{D}+\hat{V} L \hat{Y}^{F}+\widehat{V} L A^{F} L \hat{Y}^{D}+\widehat{V} L A^{F}\left(B \hat{Y}-L \hat{Y}^{D}\right)
\end{aligned}
$$

Each element in the $\widehat{V} B \widehat{Y}$ matrix represents the value added from a source countrysector directly or indirectly used in the production of final goods and services in a particular country/sector. The element of row $(s, i)$ and column $(r, j)$ in the matrix, $v_{i}^{S} b_{i j}^{s r} y_{j}^{r}$, is the total value added (direct and indirect) of sector $i$ in country s embodied in the final products produced by sector $j$ of country r. Looking at the matrix along a row yields the distribution of value added created from one country-sector that is absorbed by final goods production in all country-sectors. Looking at the matrix along a column yields the contribution of value added from all source country-sectors pairs that is embodied in final goods and services produced by a particular country/sector.

The $\hat{V} B \hat{Y}$ matrix can be decomposed into four GN by GN matrixes, each representing domestic value-added generated or foreign value-added used by the industry in its production of final products to satisfy different segments of the global market. Equation (3) identifies, for each country-sector, three types of production activities:

(1) Value added that is domestically produced and consumed $\left(\hat{V} L \hat{Y}^{D}\right)$. This value added does not involve cross border trade. An example is haircut.

(2) Value-added that is embodied in final product exports $\left(\widehat{V} L \hat{Y}^{F}\right)$. This embodied domestic factor content crosses national borders for consumption only. It is similar to 
"traditional" trade such as "French wine in exchange for England cloth", in the term proposed by Borin and Mancini (2015) ${ }^{1}$.

(3) Value-added that is embodied in exports/imports of intermediate goods and services $\left(\widehat{V} L A^{F} B \hat{Y}\right)$. Because it is used in production activities outside the source country, it is part of the cross-country production sharing activities. Based on whether the value added crosses borders once or more than once, this term can be further split into two categories $^{2}$ :

3a. Simple cross country production sharing activities $\left(\widehat{V} L A^{F} L \widehat{Y}^{D}\right)$. Domestic or/and foreign value-added cross national border for production only once. Value-added embodied in intermediate exports/imports that is used by a direct importing country to produce products that are absorbed in the country. There are no indirect exports via third countries or re-exports/re-imports of the source countries' factor contents. An example is Chinese value-added embodied in its steel exports to the US which is then used in US house construction.

3b. Complex cross country production sharing activities $\left(\hat{V} L A^{F}\left(B \hat{Y}-L \hat{Y}^{D}\right)\right)$. Domestic or/and foreign value-added embodied in intermediate exports/imports that is used by partner country to produce exports (intermediate or final) for other countries. In this case, the factor contents cross border at least twice. One example is the salaries of Apple's US designers that are embodied in the iPhones that are exported from China to the US that are ultimately bought by American consumers; Another example is Japanese value-added embodied in electronic chips installed in China-made toys that are export to the United States ${ }^{3}$.

To obtain some more intuition from Equation (3), especially what activities constitute the complex GVCs, let us look at an example of a two-country (home country s

\footnotetext{
${ }^{1}$ In Ricard's time, exports were $100 \%$ domestically produced value added, whereas today, many final product exports from a country, foreign value added is always embodied and domestically produced value added is only a part of the exports. However, using decomposition method based on input-output statistics, we are still able to compute the portion of "traditional trade analytically.

${ }^{2}$ It is important to note that the inter-country input-output table does not separate country j's domestic value added produced by foreign owned firms located in country $\mathrm{j}$ from country $\mathrm{j}$ 's value added produced by locally owned firms. This means that the decomposition is residence based rather than ownership based. In particular, valued added generated by foreign owned firms in country $\mathrm{j}$ is not considered as part of GVC activities if it does not involve cross border trade.

${ }^{3}$ Term $3 \mathrm{~b}$ can be further divided into returned domestic value added and foreign value added based on their final destinations of absorption. A detailed mathematical derivation and their relation with the measures in the existing literature are provided in Appendix A.
} 
and foreign country r) world with $\mathrm{N}$ tradable sectors. In this case, Equation (3) can be rewritten in block matrix notations as follows:

$$
\begin{aligned}
& \hat{V} B \hat{Y}=\left[\begin{array}{cc}
\hat{V}^{s} L^{s s} \hat{Y}^{s s} & 0 \\
0 & \hat{V}^{r} L^{r r} \hat{Y}^{r r}
\end{array}\right]+\left[\begin{array}{cc}
\hat{V}^{s} L^{s s} \hat{Y}^{s r} & 0 \\
0 & \hat{V}^{r} L^{r r} \hat{Y}^{r s}
\end{array}\right]+\left[\begin{array}{cc}
0 & \hat{V}^{s} L^{s s} A^{s r} L^{r r} \hat{Y}^{r r} \\
\hat{V}^{r} L^{r r} A^{r s} L^{s s} \hat{Y}^{s s} & 0
\end{array}\right] \\
& +\left[\begin{array}{cc}
\hat{V}^{s} L^{s s} A^{s r}\left(B^{r s} \hat{Y}^{s s}+B^{r r} \hat{Y}^{r s}\right) & \hat{V}^{s} L^{s s} A^{s r}\left[\left(B^{r r}-L^{r r}\right) \hat{Y}^{r r}+B^{r s} \hat{Y}^{s r}\right. \\
\hat{V}^{r} L^{r r} A^{r s}\left[\left(B^{s s}-L^{s s}\right) \hat{Y}^{s s}+B^{s r} \hat{Y}^{r s}\right] & \hat{V}^{r} L^{r r} A^{r s}\left(B^{s r} \hat{Y}^{r r}+B^{s s} \hat{Y}^{s r}\right)
\end{array}\right]
\end{aligned}
$$

The economic meaning of the first three terms can be clearly observed from the block matrixes in Equation (4): They all only involve local Leontief inverse L. The first two terms involve only country s or country r's own local inverse, implying that the production activities measured by the two terms are all local activities. The third term contains both countries local inverse as well as the direct import input coefficient matrix, implying cross-country production sharing activities between the home and foreign countries. $\mathrm{A}^{\mathrm{sr}}$ or $\mathrm{A}^{\mathrm{rs}}$ represent the direct link in one production stage.

The last term is more complex, as it includes a global Leontief inverse B, representing infinite iterations of direct input coefficient matrix A. It can be further decomposed into two sub-terms: The diagonal elements are domestic value-added that are exported first but eventually returned home; while the off-diagonal elements are reexported foreign value-added.

\subsection{Decomposition value added and final goods production}

Summing up equation (3) along the row direction, we can decompose value-added generated from each industry/country pair (GDP by industry) in terms of where it goes.

$$
V a^{\prime}=\hat{V} B Y=\underbrace{\hat{V} L Y^{D}}_{(1)-V_{-} D}+\underbrace{\hat{V} L Y^{F}}_{(2)-V_{-} R T}+\underbrace{\hat{V} L A^{F} L Y^{D}}_{(3 a)-V_{-} G V C_{-} S}+\underbrace{\hat{V} L A^{F}\left(B Y-L Y^{D}\right)}_{(3 b)-V_{-} G V C_{-} C}
$$

Summing up equation (3) along the column direction, we can decompose countrysector final goods production in terms of where the value added comes from.

$$
Y^{\prime}=V B \hat{Y}=\underbrace{V L \hat{Y}^{D}}_{(1)-Y_{-} D}+\underbrace{V L \hat{Y}^{F}}_{(2)-Y_{-} R T}+\underbrace{V L A^{F} L \hat{Y}^{D}}_{(3 a)-Y_{-} G V C_{-} S}+\underbrace{V L A^{F}\left(B \hat{Y}-L \hat{Y}^{D}\right)}_{(3 b)-Y_{-} G V C_{-} C}
$$

The first terms in both equations (5) and (6) represent value-added produced at home and absorbed by domestic final demand without involving international trade; we

\footnotetext{
${ }^{4}$ A detailed mathematical derivation of equation (5) and (6) and their relations are provided in Appendix B.
} 
label them as V_D and Y_D respectively. The second terms in Equation (5) are domestic value-added embodied in final product exports, and are labeled as V_RT and Y_RT, respectively. Both of them are domestic production activities, but V_D and V_RT from Equation (5) are the sum of value added from a country-sector used in all downstream sectors; Y_D and Y_RT from equation (6) are the value added in a country sector that sums up the value added from all upstream sectors. In general, VD and V_RT are different from Y_D and Y_RT except at the country aggregate level.

The third terms (3a) in the two equations are measures of simple GVC activities. V_GVC_S from equation (5) is domestic value-added embodied in a country-sector's intermediate exports that is used by the direct importing country to produce its domestic products that is consumed in that country, while Y_GVC_S from equation (6) is foreign value added in a country sector that is imported directly from partner countries and used for domestically consumed products. Both cross borders for production only once and are therefore referred to "simple GVC activities."

The fourth terms ( $3 b)$ in the two equations involve value added that cross borders more than once and are referred as complex GVC activities. V_GVC_C from equation (5) is domestic factor content from a country-sector that is embodied in its intermediate exports and used by a direct importing country to produce exports (intermediate or final) for other countries; Y_GVC_C from equation (6) is either returned domestic value-added or foreign value added embodied in intermediate imports used by the home country to produce its final products for either domestic use or exports. Because of indirect trade through third countries, V_GVC_C and Y_GVC_C are not the same except at their global aggregates.

The sum of the last three terms in equation (5) equals domestic value-added in gross exports via forward linkages (DVA_F) as proposed by Koopman, Wang and Wei (2014). The sum of the last two terms in Equation (6) minus returned domestic value added equals foreign value added in the exporting country's final goods production as defined by Los, Timmer and Vries (2015).

The downstream decomposition of GDP by industry based on forward linkages can be illustrated as Figure 1a; and the upstream decomposition of final goods production based on backward linkages can be depicted as Figure $1 \mathrm{~b}$. 
Figure 1a Decomposition of GDP by industry

- Which types of production and trade are Global Value Chain activities?

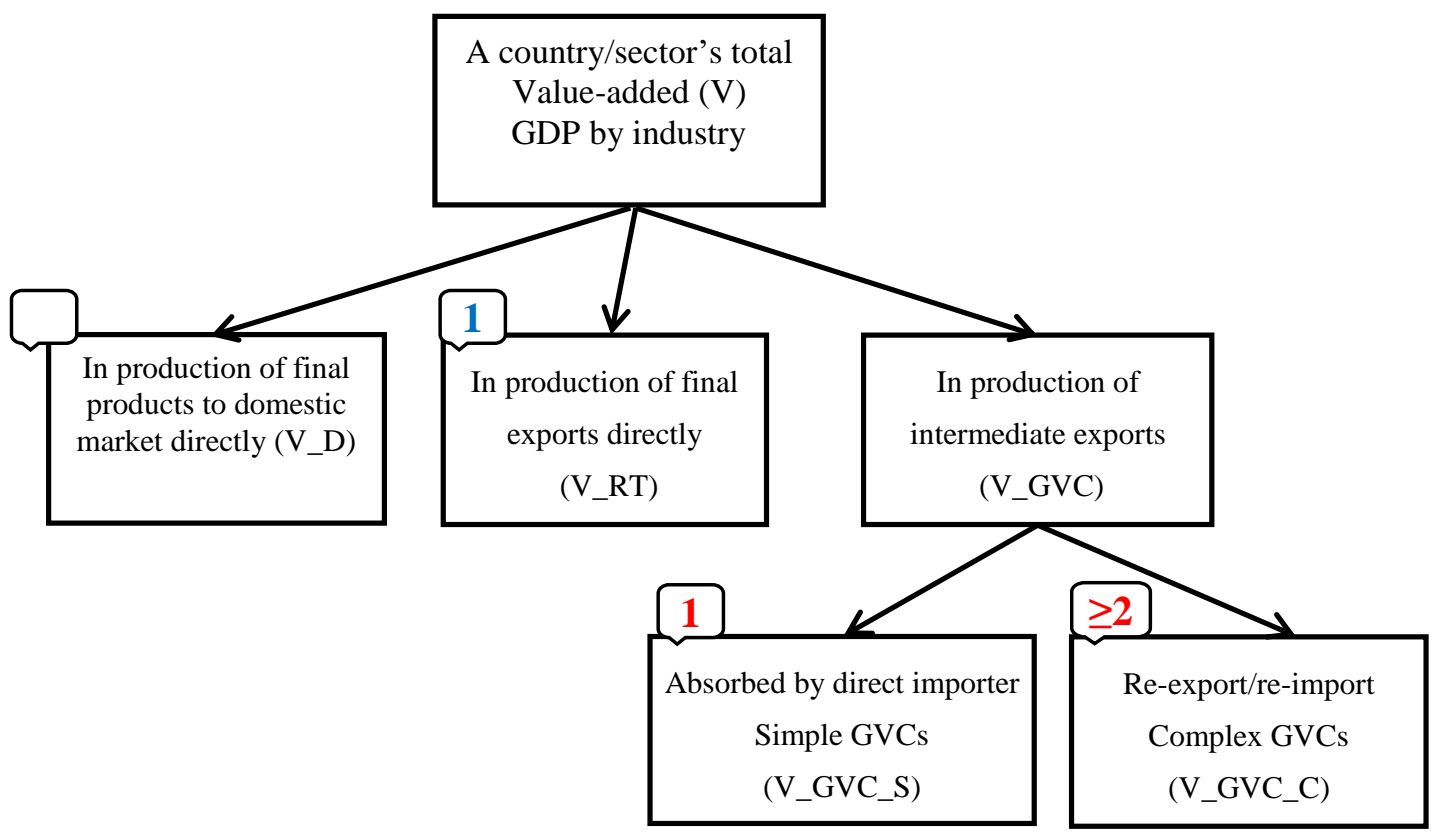

Figure 1b Decompose final goods production by country/sector --Which part of final goods production and trade belong to GVCs?

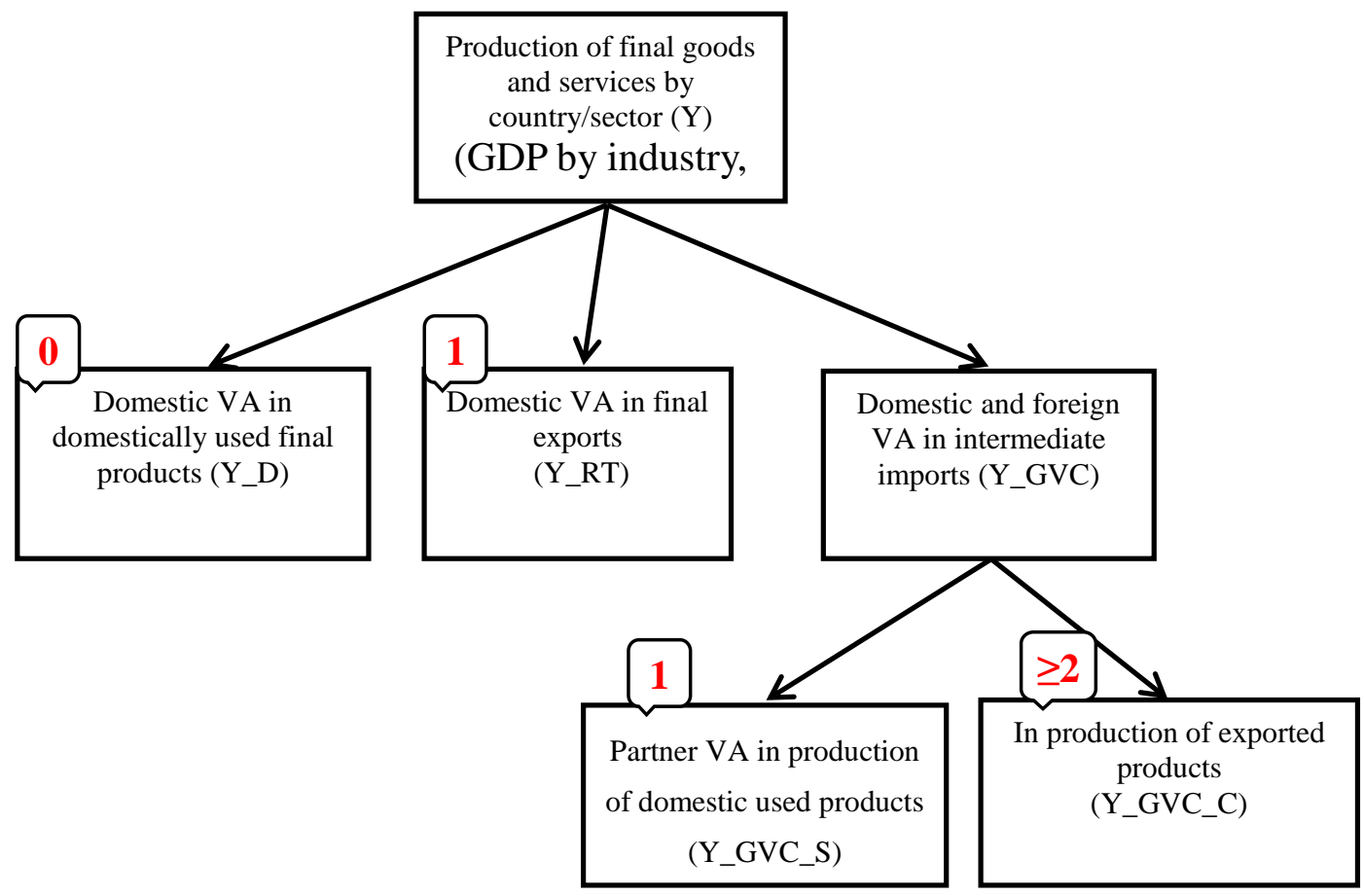




\subsection{Global Value-Chain participation indexes}

A firm can participate in international production sharing in four ways:

(1) Exporting its domestic value-added in intermediate exports used by a direct importing country to produce for domestic consumption;

(2) Exporting its domestic value-added in intermediate exports used by a direct importing country to produce products for a third country;

(3) Using other countries' value-added to produce its gross exports;

(4) Using other countries' value-added to produce for domestic use.

In the existing literature, the VS and VS1 measures (expressed as percent of gross exports), as proposed by Hummels et al., 2001, takes into account the middle two channels.

There are three areas the new indexes can improve upon. First, by excluding the first and the last channels, the conventional measures potentially omit a large portion of international production sharing activities.

Second, by using gross exports as the denominator, the shares in the conventional VS1 measures might be very high for sectors with very little direct exports (e.g., Mining and Service). In such cases, the existing measure may overestimate GVC participation for such country-sectors.

Third, the conventional measures cannot distinguish between participation in simple and complex GVC activities.

Following the two decomposition formulas in Equations (5) and (6), we can fully identify all the four possible ways a country-sector can participant in the global production network and construct indexes that help us to measure the extent to which production factors employed in a particular country-sector are involved in the global production process. Accordingly, we define a pair of GVC participation indices at a country-sector level.

The first one describes the domestic value added generated from a country-sector's GVC activities through downstream firms as share of that country-sector's total value added, and can be expressed as follows:

$$
G V C P t_{-} f=\frac{V_{-} G V C}{V a^{\prime}}=\frac{V_{-} G V C_{-} S}{V a^{\prime}}+\frac{V_{-} G V C_{-} C}{V a^{\prime}}
$$


The denominator on the right-hand-side of equation (7) is the total value-added generated in production from that country-sector pair, and the numerator is the total domestic value added of that country sector that is embodied in its intermediate exports to the world. This measure differs from the conventional VS1 measure (as percent of gross exports) in two ways: (a) it is based on value added rather than gross exports; (b) it is a production concept rather than trade.

A second participation index measures the percentage of a country-sector's total production of final goods and services that represent the value added that is involved in GVC activities through upstream firms, and can be written as follows:

$$
G V C P t t_{-} B=\frac{Y_{-} G V C}{Y^{\prime}}=\frac{Y_{-} G V C_{-} S}{Y^{\prime}}+\frac{Y_{-} G V C_{-} C}{Y^{\prime}}
$$

This measure differs from the conventional VS measure (as percent of gross exports) in two ways: (a) it is based on a net concept while VS is based on a gross concept; (b) it is a production concept instead of trade. It includes not only foreign value-added embodied in intermediate imports, reflecting the degree of foreign production factors' participation in the home country-sector's production of final products, but also domestic factor content that has returned home through international trade to satisfy domestic final demand.

For the world as a whole, the sums of its numerator over all countries and sectors in (7) and (8) equal to each other. ${ }^{5}$

In summary, this pair of GVC participation indices provides a complete picture of a country's participation in GVCs based on whether the production factor content crosses national borders for production. They take into account both forward and backward industrial linkages. The former measures domestic value added generated from GVCs production and trade activities as a share of total sector value added (GDP)., whereas the latter measures the percentage of a country's final goods production contributed by both domestic and foreign factors that involve cross country production sharing activities. The relative values of the two indices indicate a country-sector's position in the global production network. For instance, a higher degree of forward participation than backward

\footnotetext{
${ }^{5}$ The mathematical proof is provided in Appendix C.
} 
participation implies that the country/sector is more actively engaged in upstream production activities in GVCs.

\section{Numerical Results}

In this section, we apply the two GVC participation measures to the WIOD data (2016 version, see Timmer et al., 2016, for an explanation of the database), which covers 44 countries and 56 industries over the time period from 2000 to 2014. The indexes can be computed at both the most aggregated "world" level and a more disaggregated "bilateral-sector" level. We will report a series of examples at various levels of disaggregation.

\subsection{Traditional indexes}

The share of VS and VS1 in gross exports, as proposed by Hummels et al. (2001), are used to measure the extent of GVC participation by Koopman et al. (2010). Taking the top 3 countries in terms of GDP (United Statas, China and Japan) and a typical energy-exporting country (Russia) as examples, the VS and VS1 ratios shown in Figure 2 can provide us with useful information of GVC participation from at least two aspects: (1) Generally speaking, the degree of participation for most countries increase over the time period 2001 to 2011; (2) The upward trend of Vertical Specification has been temporarily interrupted by the global financial crisis (2009), and slowed down or reversed after the year 2012. 
Figure 2 VS and VS1 ratios, 2000 to 2014

VS1 as \% of Exports

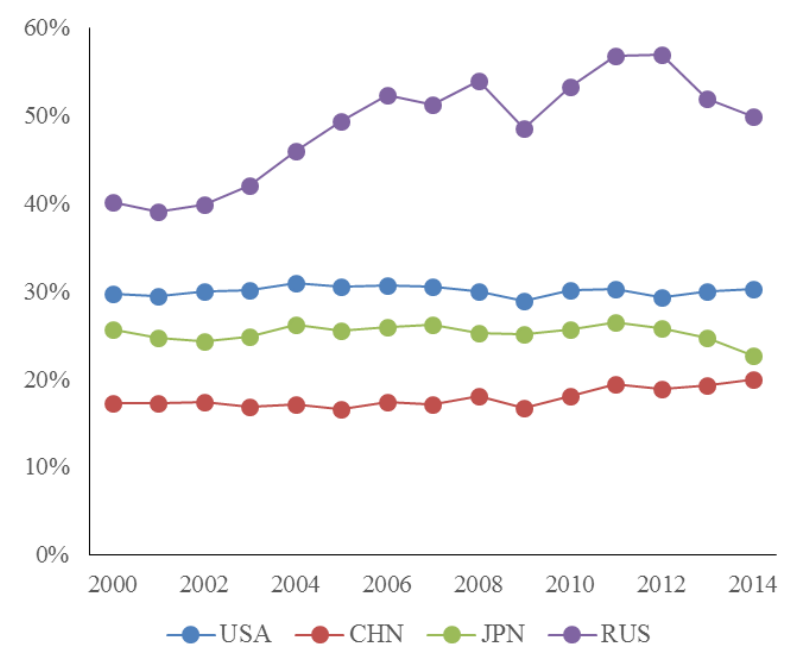

VS as \% of Exports

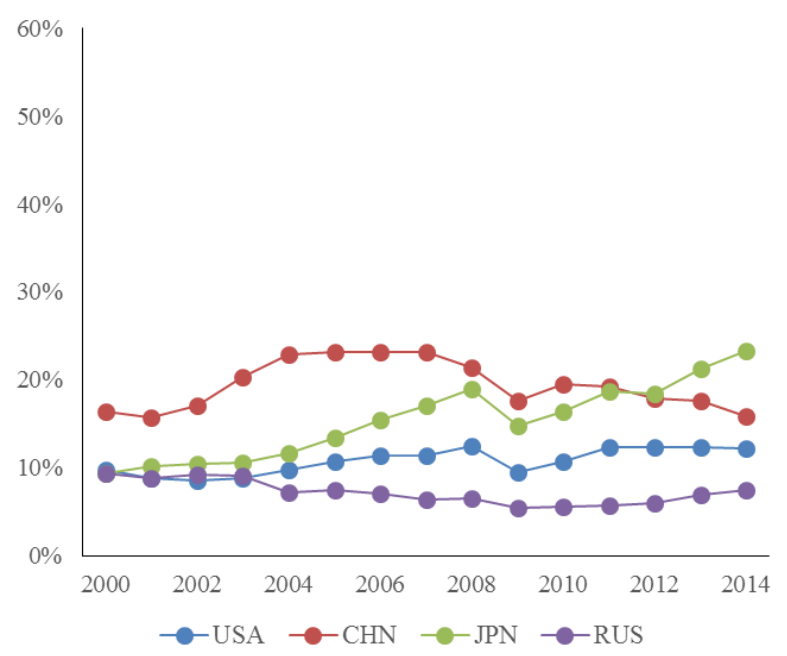

\subsection{The new GVC Participation indexes}

The forward linkage based participation index as address the question of "What percentage of production factors employed in a country-sector pair has been involved in cross country production sharing activities?" The backward linkage based participation index can be understood as answering the question of "What percentage of final products produced by a country-sector that comes from GVC activities?"

\section{(1) Country level}

We continue with the examples of the United States, China, Japan and Russia. Figure 3 plots both participation indexes from 2000-2014. 
Figure 3 Forward/Backward Participation Indexes, 2000 to 2014
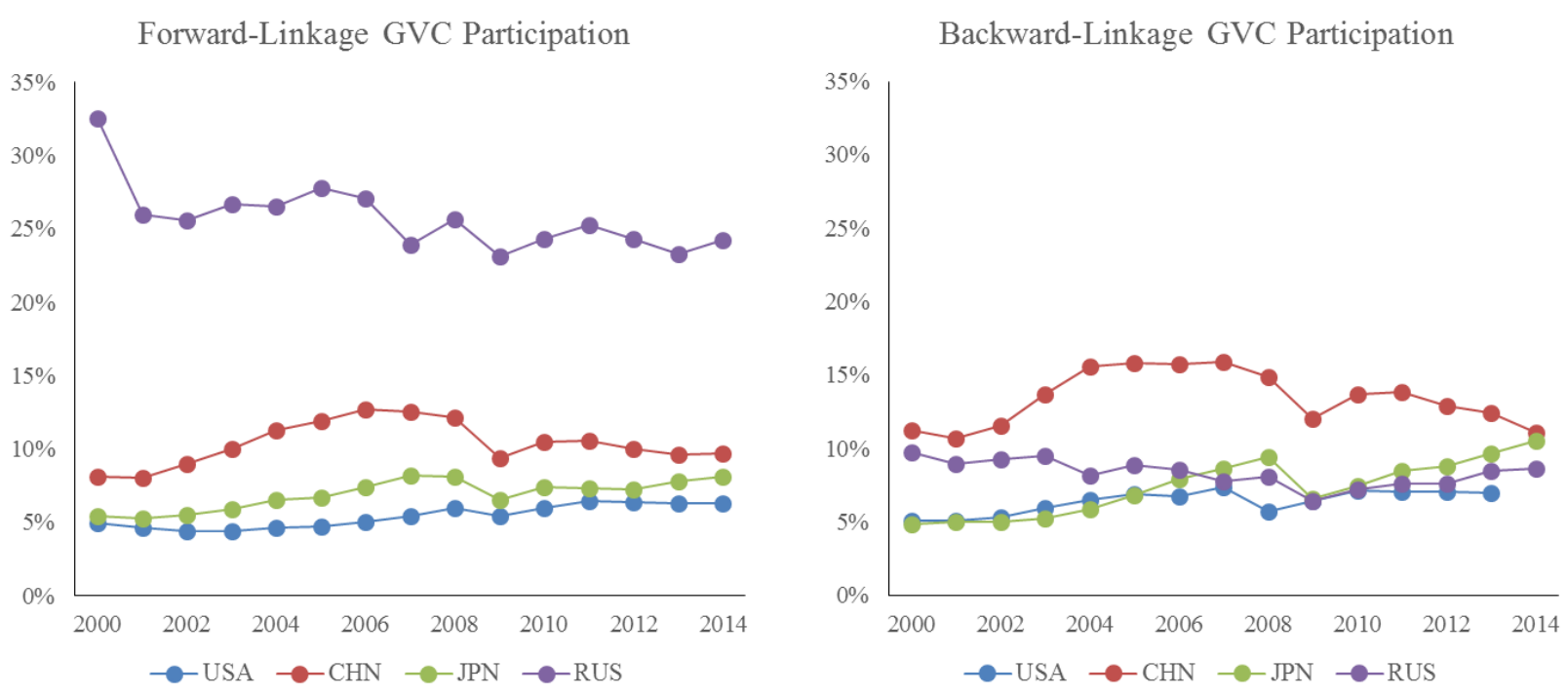

While there are similarities between the new and the conventional indices, there are also clear differences between the two. For instance, while the new index shows that Russian's participation based on forward linkages has been on the decline, the conventional VS1 measure might give the opposite impression. As another example, China shows a higher degree of forward participation than the United States and Japan according to the new measure, but the conventional VS1 measure would give the opposite result. One reason is a much higher ratio of gross exports to GDP for China than for the other two countries. The traditional measure, by using gross exports as the denominator, under-estimates China's GVC participation relative to the US and Japan.

We can visualize the forward and backward GVC participation indexes jointly in a scatterplot as shown in Figure 4. The two red dotted lines indicate the world's average forward and backward participation ratios. Since most countries fall along the 45-degree line, we conclude that countries that have a high degree of forward participation also tends to have a high degree of backward participation. Major resource exporters such as Norway, Russia and Australia, deviate from the 45-degree line from the above: since natural resources are in the most upstream sectors, these economies tend to have much higher degree of forward participation than backward participation. 
Figure 4 GVC Participation Indicator, Country Level, 2014

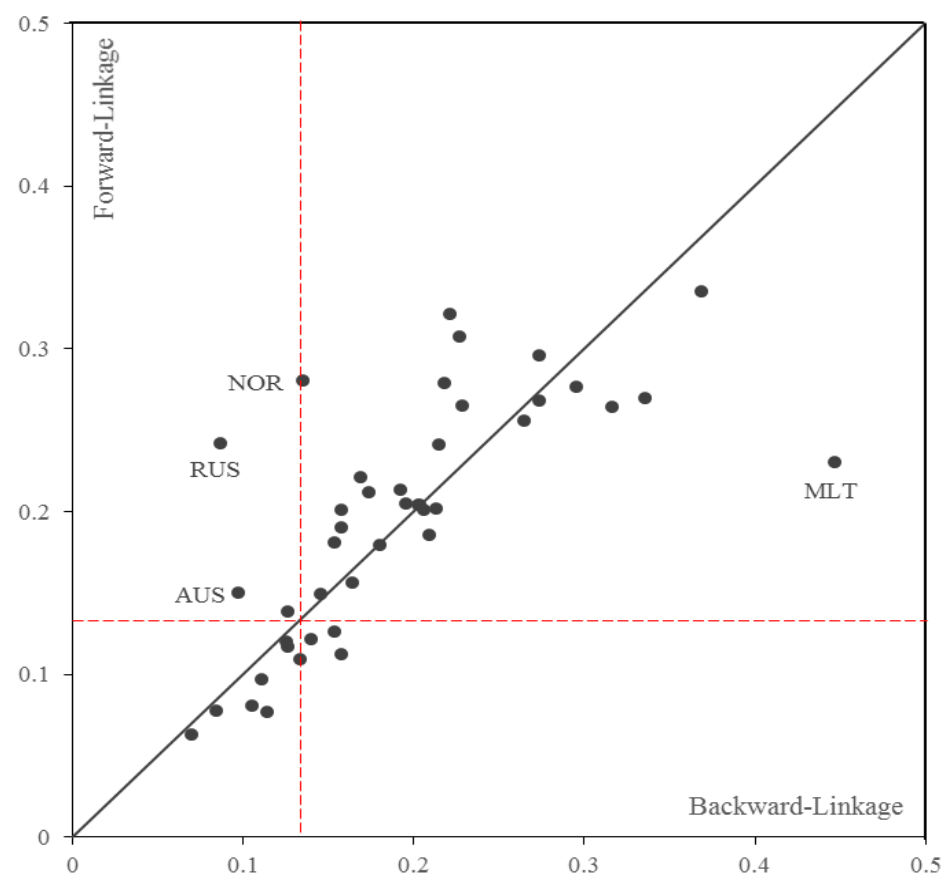

\section{(2) Sectoral level}

The intensity of GVC participation varies by sector. Table $2 \mathrm{a}$ and $2 \mathrm{~b}$ reports both GVC participation indexes by four sector groups (Agriculture, Mining, Manufacturing and services) and their changes over 15 years. In 2014, mining simultaneously has the highest forward participation ratio and second lowest backward participation ratio (48.1\% and $11.3 \%$, respectively), which is consistent with its upstream position in global production network. Manufacturing has the highest backward linkage based participation ratio $(24.6 \%)$ and second highest forward linkage based index (24.1\%); this suggests that manufacturing both produces and uses intermediate manufacturing products.

The service sector has the lowest participation ratios for both the forward and backward linkages, but its participation ratio has grown relatively fast. 
Table 2a GVC Participation Indexes at sectoral level (Forward Linkage)

\begin{tabular}{|c|c|c|c|c|c|c|c|c|c|}
\hline \multirow{4}{*}{ Sector } & \multicolumn{3}{|c|}{ GVCPt_f } & \multicolumn{3}{|c|}{ Simple GVC } & \multicolumn{3}{|c|}{ Complex GVC } \\
\hline & \multirow{3}{*}{2000} & \multirow{3}{*}{2014} & 2014 & \multirow{3}{*}{2000} & \multirow{3}{*}{2014} & \multirow{3}{*}{$\begin{array}{c}2014 \\
\text { over } \\
2000\end{array}$} & \multirow{3}{*}{2000} & \multirow{3}{*}{2014} & \multirow{3}{*}{$\begin{array}{l}2014 \\
\text { Over } \\
2000 \\
\end{array}$} \\
\hline & & & Over & & & & & & \\
\hline & & & 2000 & & & & & & \\
\hline Agriculture & $9.2 \%$ & $10.7 \%$ & $1.5 \%$ & $6.8 \%$ & $7.5 \%$ & $0.7 \%$ & $2.4 \%$ & $3.3 \%$ & $0.9 \%$ \\
\hline Mining & $50.3 \%$ & $48.1 \%$ & $-2.2 \%$ & $35.2 \%$ & $30.1 \%$ & $-5.1 \%$ & $15.1 \%$ & $18.0 \%$ & $2.9 \%$ \\
\hline Manufacturing & $20.4 \%$ & $24.1 \%$ & $3.7 \%$ & $11.9 \%$ & $14.0 \%$ & $2.1 \%$ & $8.5 \%$ & $10.1 \%$ & $1.7 \%$ \\
\hline Service & $6.7 \%$ & $8.7 \%$ & $2.0 \%$ & $4.3 \%$ & $5.4 \%$ & $1.1 \%$ & $2.3 \%$ & $3.3 \%$ & $0.9 \%$ \\
\hline \multicolumn{10}{|c|}{ Table 2b GVC Participation Indexes at sectoral level (Backward Linkage) } \\
\hline \multirow{4}{*}{ Sector } & \multicolumn{3}{|c|}{ GVCPt_b } & \multicolumn{3}{|c|}{ Simple GVC } & \multicolumn{3}{|c|}{ Complex GVC } \\
\hline & & & 2014 & & & 2014 & & & 2014 \\
\hline & 2000 & 2014 & Over & 2000 & 2014 & over & 2000 & 2014 & Over \\
\hline & & & 2000 & & & 2000 & & & 2000 \\
\hline Agriculture & $9.5 \%$ & $10.0 \%$ & $0.6 \%$ & $6.9 \%$ & $6.7 \%$ & $-0.3 \%$ & $2.6 \%$ & $3.4 \%$ & $0.8 \%$ \\
\hline Mining & $10.9 \%$ & $11.3 \%$ & $0.4 \%$ & $6.7 \%$ & $8.2 \%$ & $1.5 \%$ & $4.3 \%$ & $3.1 \%$ & $-1.2 \%$ \\
\hline Manufacturing & $20.6 \%$ & $24.6 \%$ & $4.0 \%$ & $9.5 \%$ & $10.7 \%$ & $1.2 \%$ & $11.1 \%$ & $13.9 \%$ & $2.8 \%$ \\
\hline Service & $7.5 \%$ & $10.3 \%$ & $2.8 \%$ & $5.7 \%$ & $7.4 \%$ & $1.7 \%$ & $11.1 \%$ & $13.9 \%$ & $2.8 \%$ \\
\hline
\end{tabular}

Across the sectors, we can also plot the forward participation ratios against the backward participation ratios. Figure 5 shows such a plot for 2014. Generally speaking, most service sectors (represented by the green dots) tend to in the lower left corner, meaning that they have low participation in GVC activities by either measure. Mining (the purple dot) is in the upper left corner, indicating a high degree of forward participation but a low degree of backward participation. In comparison, many manufacturing sectors (red dots) tend to be in the upper right portion of the graph, reflecting their active participation in GVCs both as producers and buyers of intermediate goods. 
Figure 5 GVC participation Indexes, Sectoral Level, 2014

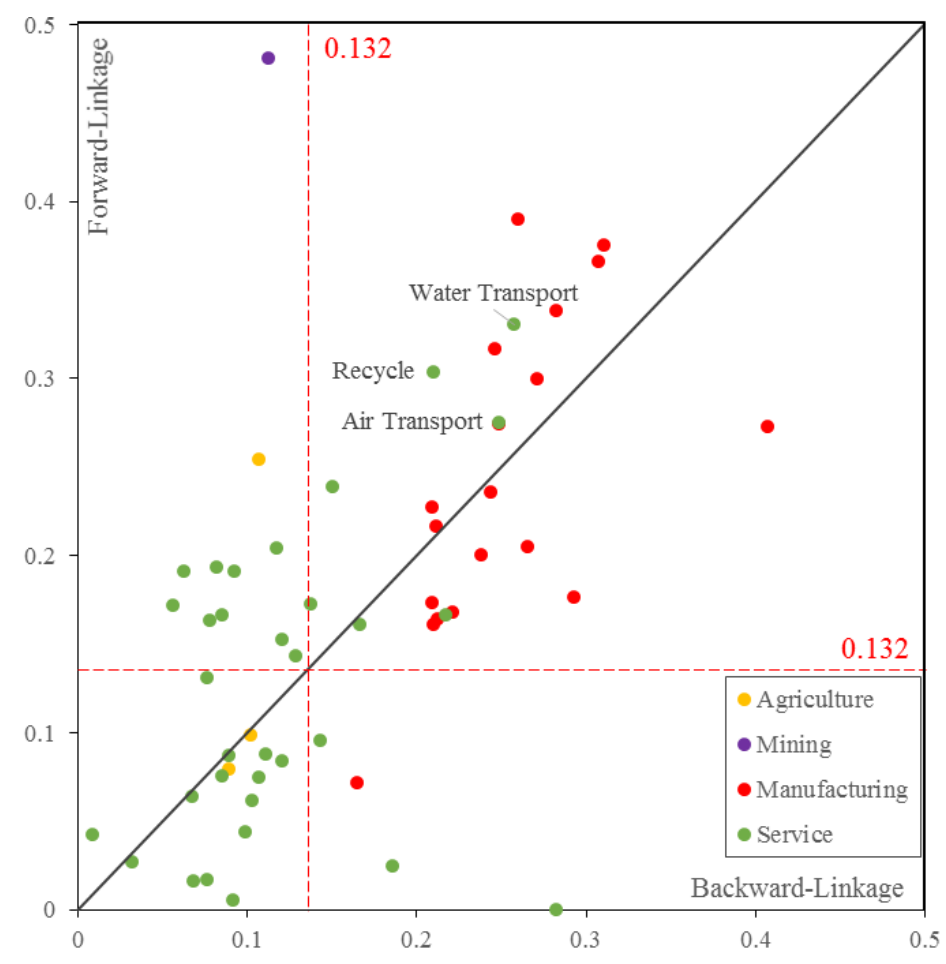

\section{(3) Country-Sector level}

We can compute GVC participation at the country-sector level. As an illustration, we pick two sectors - "refined petroleum" and "machinery and equipment" for six countries in Table 3.

Since Russia is a major energy producer and exporter, its refined petroleum's forward participation ratio, at $38.7 \%$, is the highest among the six countries, while its backward participation ratio is only $6.2 \%$.

Japan shows a reverse pattern in refined petroleum: it has a high backward participation ratio $(56.2 \%)$ but a relatively low forward participation ratio.

In machinery and equipment, Germany is revealed as the main global powerhouse as a supplier. Its forward participation ratio at $34.1 \%$ is higher not only than China and India (13.1\% and $10.6 \%$, respectively) but also than Japan and the United States $(19.4 \%$ and $16.4 \%$, respectively).

The backward participation ratios are also informative. For developing countries such as China and India, their backward participation in GVC activities related to machinery and equipment tends to be stronger than their forward participation; this is 
consistent with the observation that they rely more on imported parts and components from advanced countries than they can provide to the world as suppliers. In comparison, Germany's backward participation ratio is notably lower than its forward participation. On the other hand, for the United States and Japan, the backward and forward participation ratios are more balanced.

Table 3 Sectoral Level Participation Indexes, Forward/Backward Linkage

\begin{tabular}{ccc}
\hline & Forward Linkage Based Participation Index (GVCPt_f) \\
\cline { 2 - 3 } & Refined Petroleum & Machinery and Equipment \\
\hline CHN & $15.7 \%$ & $13.1 \%$ \\
DEU & $36.2 \%$ & $\mathbf{3 4 . 1 \%}$ \\
IND & $26.8 \%$ & $10.6 \%$ \\
JPN & $19.9 \%$ & $19.4 \%$ \\
RUS & $\mathbf{3 8 . 7 \%}$ & $17.1 \%$ \\
USA & $17.2 \%$ & $16.4 \%$ \\
\hline & Backward Linkage Based Participation Index (GVCPt_b) \\
\cline { 2 - 3 } & Refined Petroleum & Machinery and Equipment \\
\hline CHN & $23.9 \%$ & $\mathbf{2 9 . 0 \%}$ \\
DEU & $72.4 \%$ & $25.1 \%$ \\
IND & $57.7 \%$ & $19.7 \%$ \\
JPN & $56.2 \%$ & $17.5 \%$ \\
RUS & $\mathbf{6 . 2 \%}$ & $18.9 \%$ \\
USA & $28.5 \%$ &
\end{tabular}

CHN=China; DEU=Germany; IDN=Indonesia; JPN=Japan; RUS=Russia; USA=United States

For each sector, we can generate a scatter plot of the two participation ratios across countries. Figure 6 presents the results for four sector groups. Generally speaking, for manufacturing, service and agriculture sectors, most countries are distributed around the 45-degree line. For most countries, the average level of GVC participation is higher in manufacturing sector than that in the service or agriculture sectors. In the mining sector, the forward participation ratio is generally higher than backward participation for most countries. 
Figure 6 GVC participationIndexes, Country-Sector Level, 2014
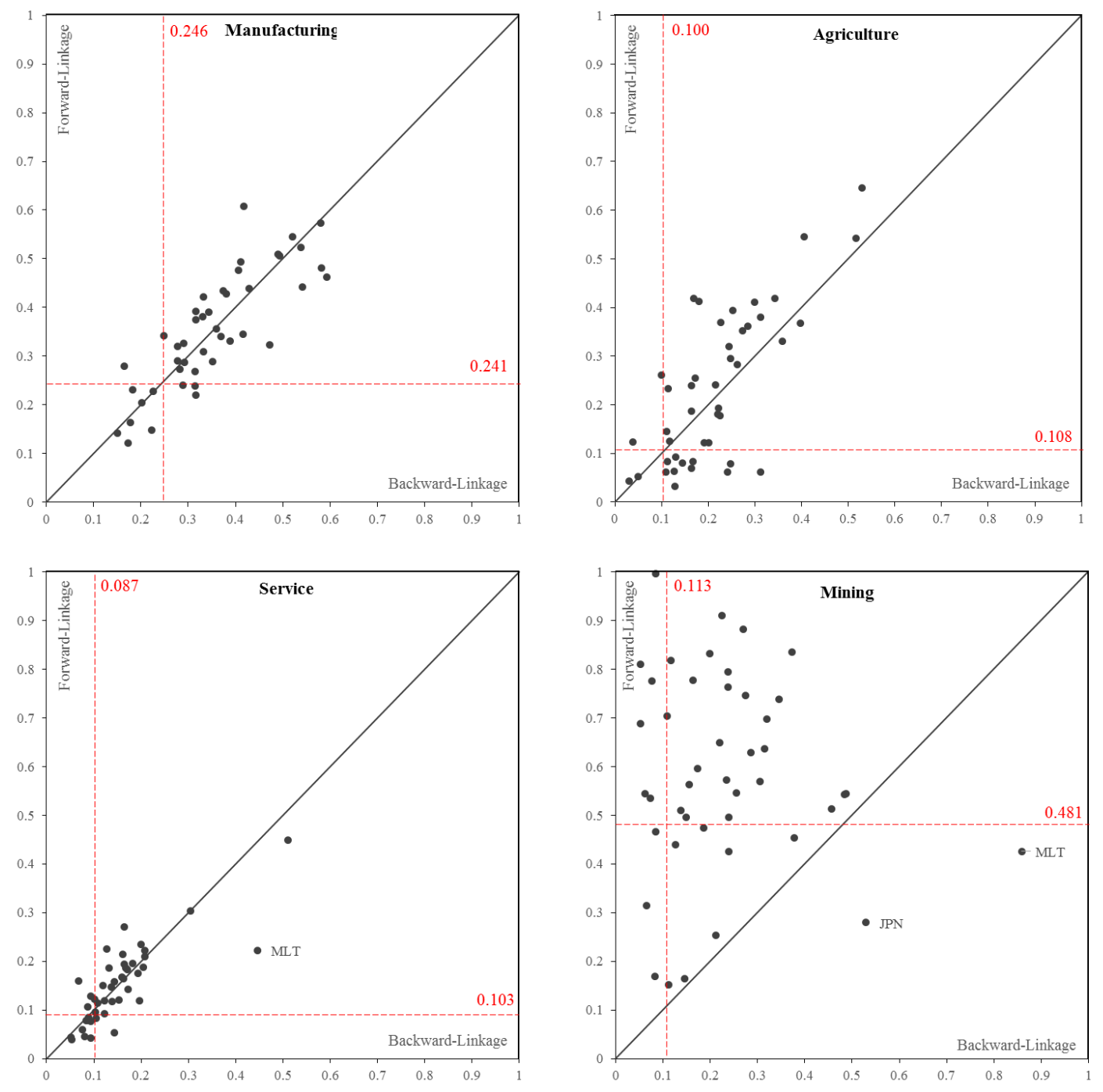

\subsection{Advantages of the new "GVC Participation Index"}

\section{(1) Correcting a bias in traditional indexes}

As mentioned previously, using gross exports as the denominator may lead to an upward bias at the bilateral/sectoral level. For comparison, we compute both forward linkage based participation index, the conventional VS1 (as share of gross exports) and the new participation index GVCPt_f, and GVC activities as share of sector GDP, respectively. As shown in Table 4, the VS1 shares for 7 out of 56 industries are substantially larger than $100 \%$. These industries have one thing in common: a great proportion of their value added is exported indirectly, which is embodied in other 
industries' exports. This makes the conventional VS1 measure less desirable at the sector or bilateral sector level.

The upward bias is more pronounced for utility and service sectors, as a large proportion of their value added is exported indirectly.

Table 4 Comparison between Traditional and New Measures in US sectors, 2014

\begin{tabular}{ccc}
\hline WIOD 2016 Sector label & GVCPt_F & VS1 \\
\hline Repair and installation & $1.7 \%$ & $1334.0 \%$ \\
Electricity and gas supply & $3.6 \%$ & $330.9 \%$ \\
Water supply & $3.6 \%$ & $322.7 \%$ \\
Construction & $0.6 \%$ & $1748.0 \%$ \\
Wholesale and retail trade & $1.3 \%$ & $248.1 \%$ \\
Real estate & $1.2 \%$ & $439.6 \%$ \\
Legal and accounting activities & $9.4 \%$ & $107.0 \%$ \\
\hline
\end{tabular}

Table 5 Comparison between Traditional and New Participation Indexes for Three Typical Sectors

\begin{tabular}{|c|c|c|c|c|c|c|}
\hline & \multicolumn{2}{|c|}{ Electricity, Gas and Water } & \multicolumn{2}{|c|}{ Retail Trade } & \multicolumn{2}{|c|}{ Leather and Footwear } \\
\hline & VS1 & GVCPt_F & VS1 & GVCPt_F & VS1 & GVCPt_F \\
\hline AUS & $630.2 \%$ & $14.4 \%$ & $635.6 \%$ & $11.9 \%$ & $21.5 \%$ & $32.8 \%$ \\
\hline BRA & $3521.6 \%$ & $6.3 \%$ & $1131.2 \%$ & $4.0 \%$ & $21.6 \%$ & $8.6 \%$ \\
\hline CAN & $101.9 \%$ & $19.5 \%$ & $15.6 \%$ & $18.0 \%$ & $5.5 \%$ & $37.5 \%$ \\
\hline $\mathrm{CHN}$ & $396.2 \%$ & $12.0 \%$ & - & - & $5.0 \%$ & $12.3 \%$ \\
\hline DEU & $101.8 \%$ & $18.6 \%$ & $77.1 \%$ & $15.9 \%$ & $10.9 \%$ & $42.4 \%$ \\
\hline ESP & $306.4 \%$ & $15.0 \%$ & $29.8 \%$ & $7.8 \%$ & $7.1 \%$ & $22.3 \%$ \\
\hline FRA & $148.6 \%$ & $14.6 \%$ & $46.9 \%$ & $7.2 \%$ & $5.7 \%$ & $25.2 \%$ \\
\hline GBR & $273.1 \%$ & $10.9 \%$ & $62.0 \%$ & $13.7 \%$ & $16.7 \%$ & $20.8 \%$ \\
\hline IND & $3419730.0 \%$ & $8.5 \%$ & $73.2 \%$ & $7.2 \%$ & $6.5 \%$ & $11.4 \%$ \\
\hline ITA & $250.2 \%$ & $14.9 \%$ & $58.6 \%$ & $7.8 \%$ & $11.0 \%$ & $30.0 \%$ \\
\hline JPN & $1082.2 \%$ & $9.2 \%$ & $3263.9 \%$ & $9.7 \%$ & $31.8 \%$ & $23.2 \%$ \\
\hline KOR & $363.7 \%$ & $19.8 \%$ & $45.3 \%$ & $23.7 \%$ & $17.2 \%$ & $43.3 \%$ \\
\hline MEX & $411.8 \%$ & $8.8 \%$ & $33.4 \%$ & $8.2 \%$ & $3.7 \%$ & $11.8 \%$ \\
\hline RUS & $562.1 \%$ & $26.9 \%$ & $146.2 \%$ & $14.6 \%$ & $20.6 \%$ & $4.6 \%$ \\
\hline USA & $330.6 \%$ & $3.6 \%$ & $248.1 \%$ & $1.3 \%$ & $13.7 \%$ & $12.3 \%$ \\
\hline
\end{tabular}


USA=United States; CHN=China; JPN=Japan; DEU=Germany; FRA=France; GBR=United Kingdom; BRA=Brazil; ITA=Italy; IND=India; RUS=Russia; CAN=Canada; ESP=Spain; AUS=Australia; MEX=Mexico; KOR=Korea;

Table 5 lists 15 largest countries ranking by GDP to show the comparison between traditional VS1 ratio and the new forward linkage based GVC participation index.

\section{(2) Differentiating "simple" and "complex" GVC participation}

As discussed in section 2, the domestic value added in gross intermediate exports of a country can be decomposed into two major parts: DVA crossing the national border for production only once (GVC_S), representing the type of cross border specialization that is relatively simple; DVA cross border two or more times (GVC_C, representing the type of cross border specialization that is more complex, which can be further decomposed into two parts based on where these embodied factor content ultimately absorbed Traditional GVC participation indexes cannot make such distinguish, while by our newly defined indexes, both can be identified and quantified.

As illustrate by figure 7, the "simple" and "complex" parts of GVC participation are different in size and the trend of change. The simple part takes a relatively large proportion, but its relative importance is diminishing over time for almost all countries in the sample. Instead, the domestic value added exported via complex production sharing activities is increasing dramatically.

Figure 7 Simple GVC production activities as a share of total GVC production activities (1995-2014)

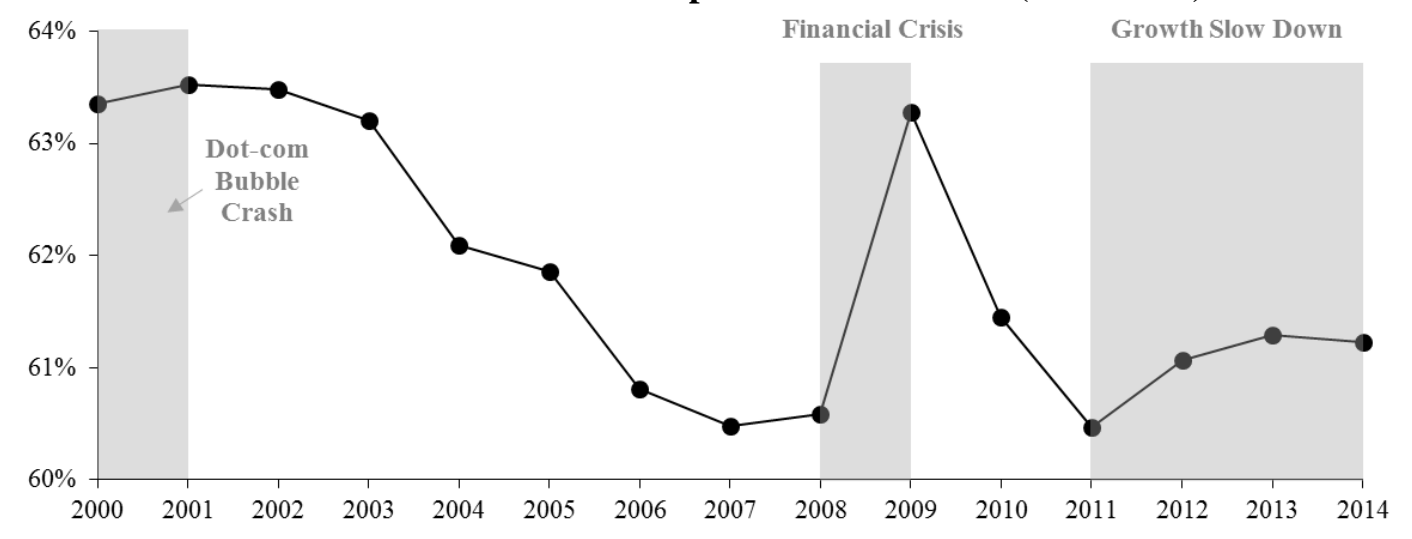


In addition, the relative sizes of returned factor content in total GVC production activities in different countries may reflect the different roles played in the GVCs by different countries. Taking 10 countries with largest GDP in year 2014 as examples, as shown in Figure 8, factor content that "re-imported and absorbed domestically," accounts for a substantially larger proportion in the US, followed by China and Germany, as the US and Germany are controlling both ends (design and sales) of the value chain, and China serves as the "world's factory" and the world's largest consumption market.

\section{Figure 8 The Share of Returned Value Added in total GVC Production Activities}

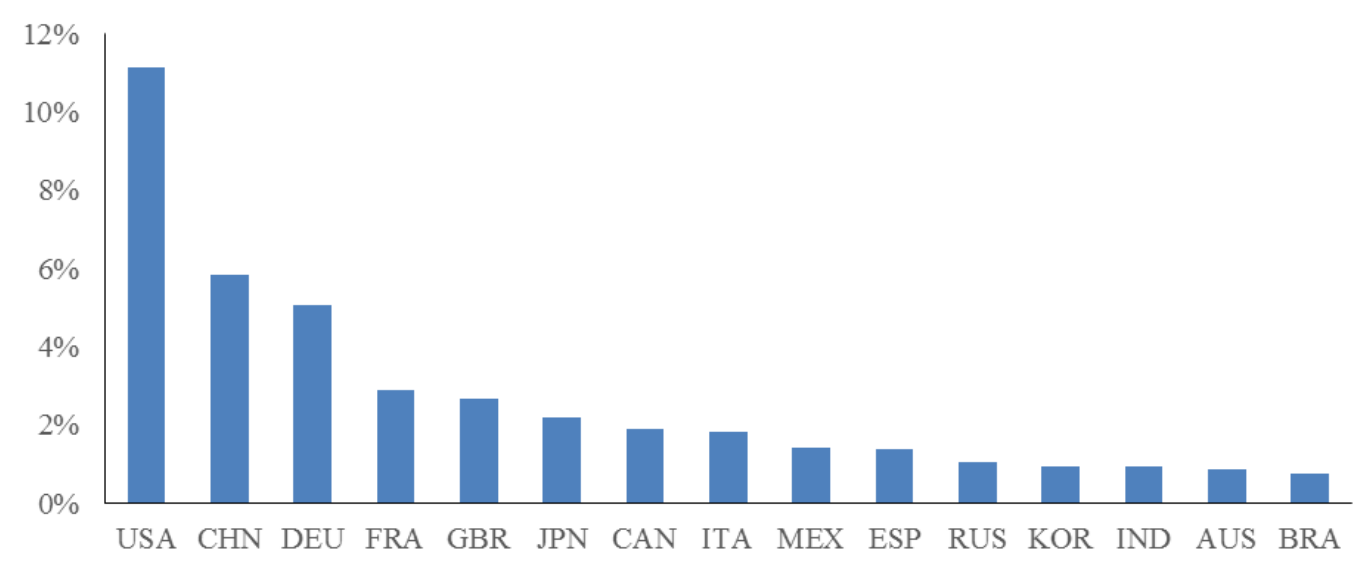

\section{Application: Economic Growth and GVC Participation}

\subsection{Salient facts}

The world economy expanded relatively fast from 2000 to 2007, experienced a severe global financial crisis during 2008-2009, which is followed by a slow but uneven recovery afterwards. We use our decomposition formulas in Equations (5) and (6) and trace out the evolution of the types of production activities during this period. The results are reported in Figure 9.

A few patterns are noteworthy. First, pure domestic activities (use of domestic factors to produce for domestic final demand) still account for the lion share of overall production activities, but its relative importance is decreasing over time (Figure 9). Second, among the three parts of production related to international trade, value added in traditional trade does not increase as fast as value added in GVC trade, and the share of value added involved in complex GVCs exhibit the fastest increase. Third, the shares of 
value added in all types of trade suffer a decline during the global financial crisis of 2008-2009 (and correspondingly, the share of value added in production for domestic demand exhibits an increase in the same period). The recovery of the GVC trade after 2009 was slow and exhibit another phase of decline after 2011. This pattern is especially pronounced for value added in complex GVC activities.

Figure 9: Evolving Trends of Different Production Activities as a Share of Global GDP (2000-2014)

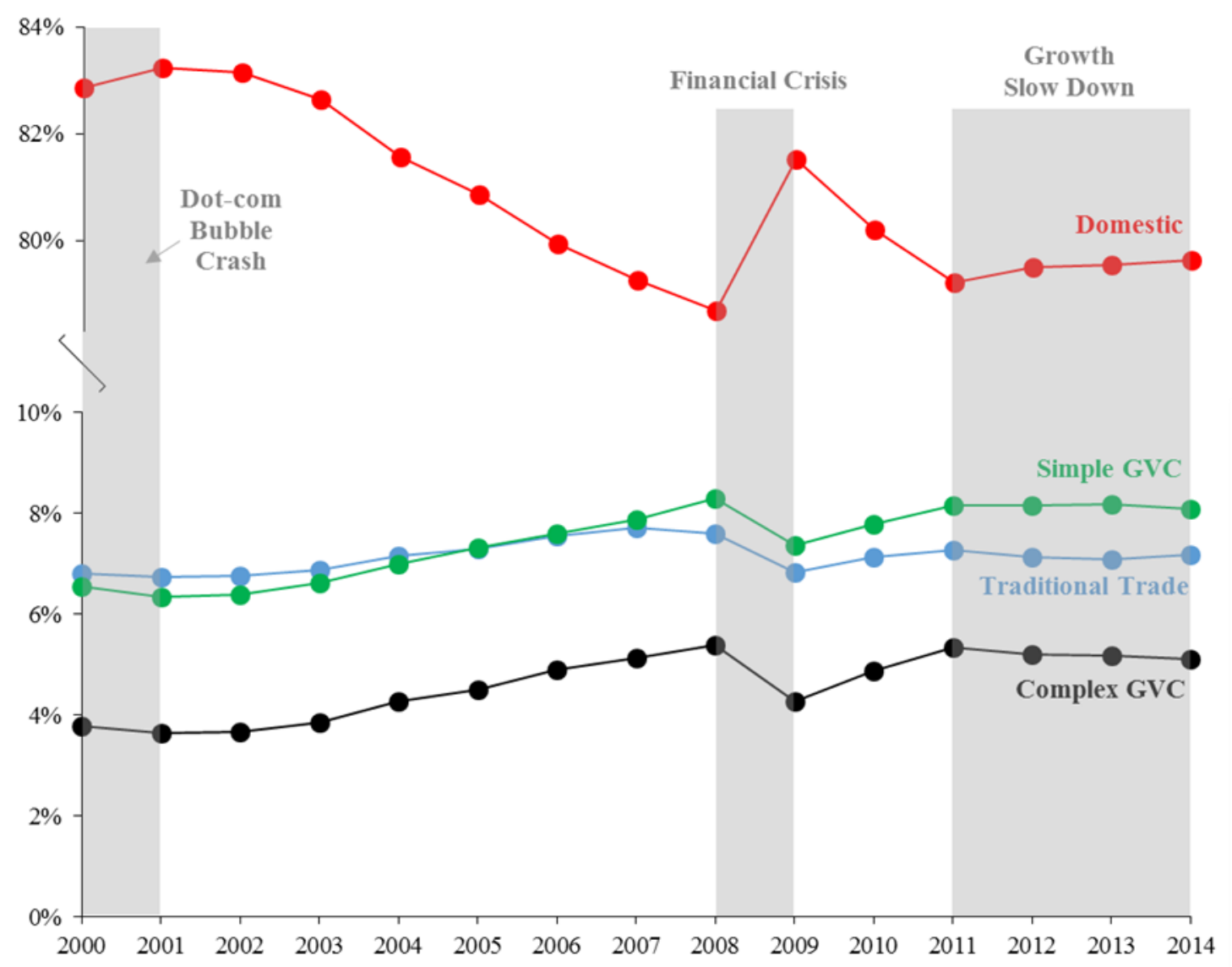

To see these patterns from another angle, we present annual growth rates for value added in different types of production activities (Figure 10). During 2001-2008, there had been a dramatic expansion of GVC activities, especially the complex production-sharing activities. The global financial crisis produced a contraction of world production and world trade in 2009, and the decline was the steepest for complex GVC trade, followed by simple GVS trade. A rapid recovery of GVC activities was observed for two years (2010-2011) following the global financial crisis, the growth turned lukewarm since 2012. 
Figure 10 Nominal growth rates of different value added creation activities during the global business cycle, global level (2000-2014)

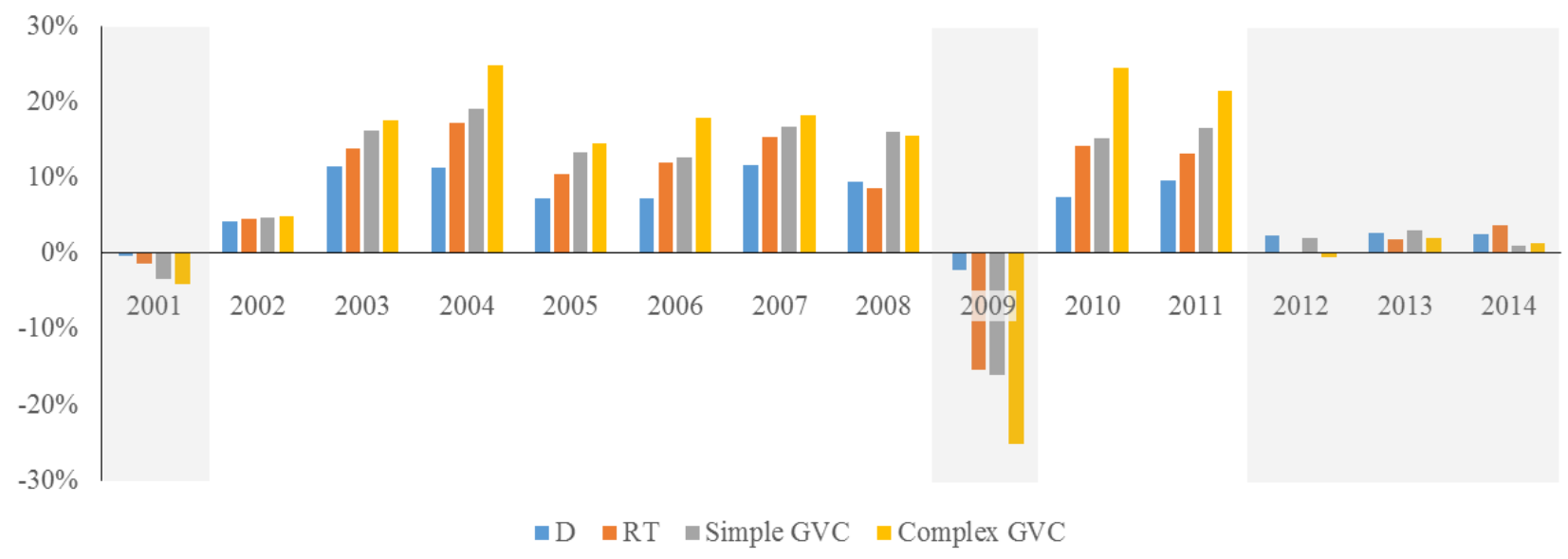

We can investigate the evolution of value added in different types of production activities by sector; this is useful if one wonders whether the picture in Figure 10 is dominated by commodity price swings over time.

We report the sector-level patterns on shares of value added in different types of activities in Figures 11a and 11b. Across all sectors, before the global financial crisis, the share of value added in trade, especially in complex GVC trade, grew fast (which produce a corresponding decline in the share of value added in production for domestic demand). The global financial crisis produced a sharp reversal of this pattern, but the precrisis pattern resumed during 2010-2011, before it becomes bogged down again after 2012.

Figure 11a: Average Annual Growth Rates of Different Activities of Value Added Creation during Recent Global Business Cycle, Sector Level
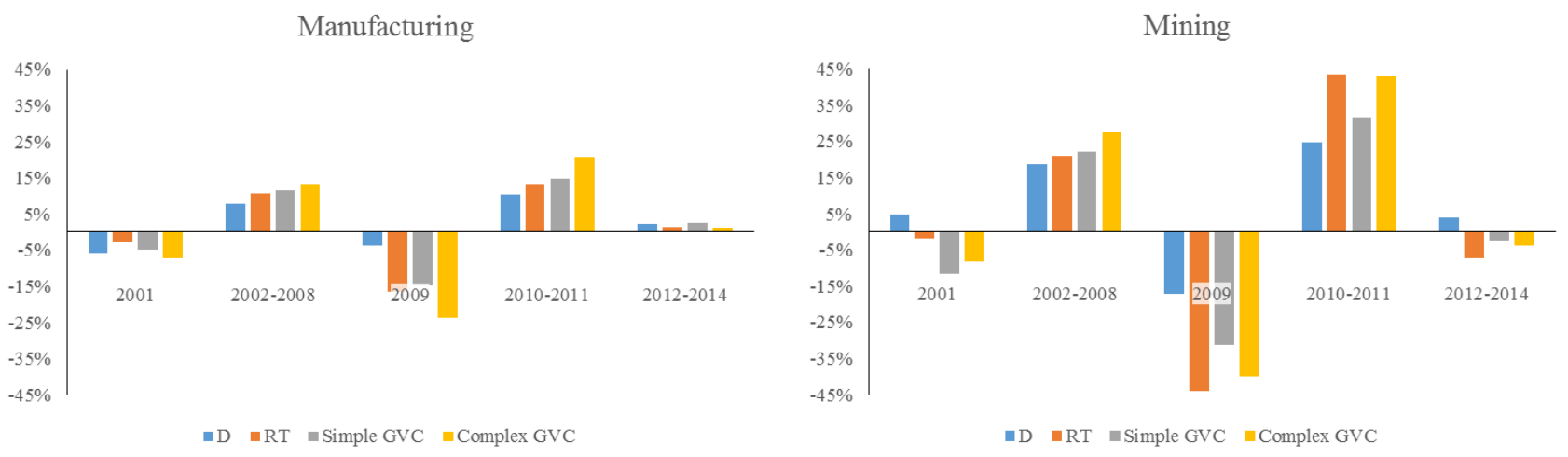

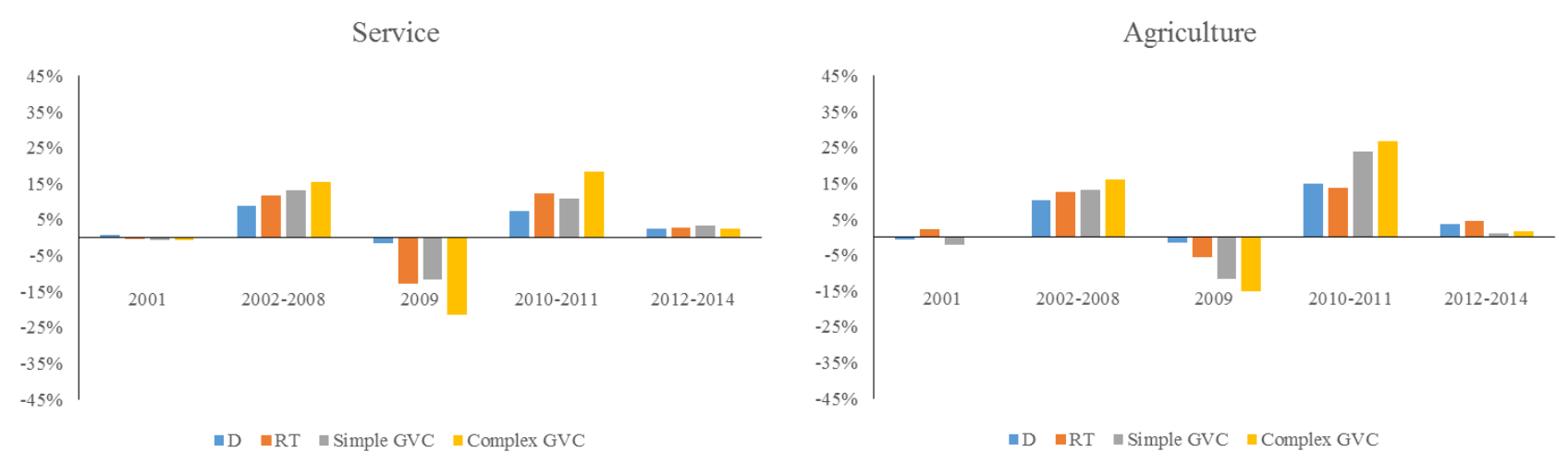

Figure 11b Structure changes in different types of value added creation activities as a Share of GDP, Sectoral Level

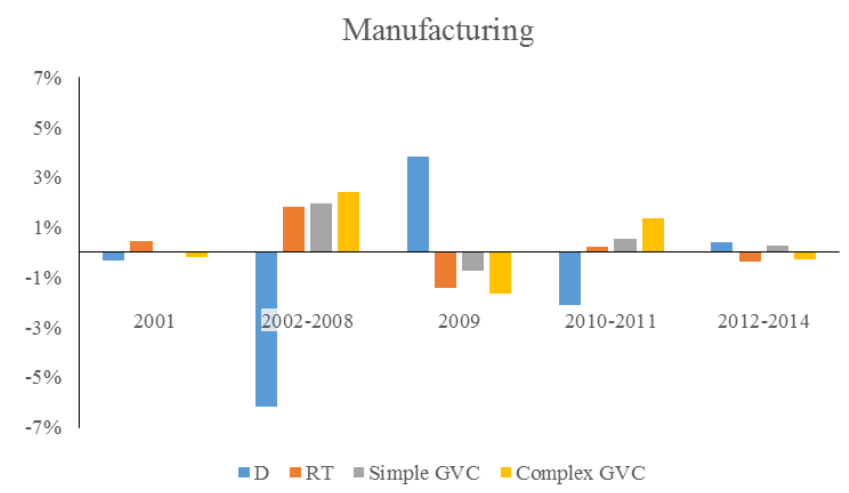

Service

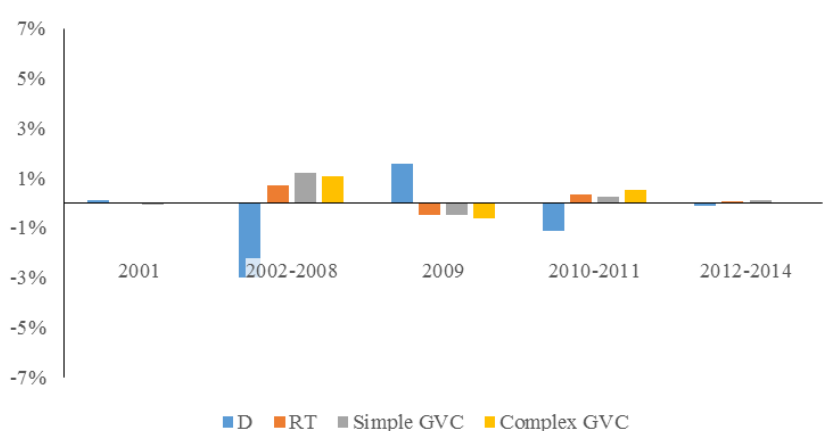

$\because \mathrm{D} \quad \because \mathrm{RT} \quad$-Simple GVC $\|$ Complex GVC
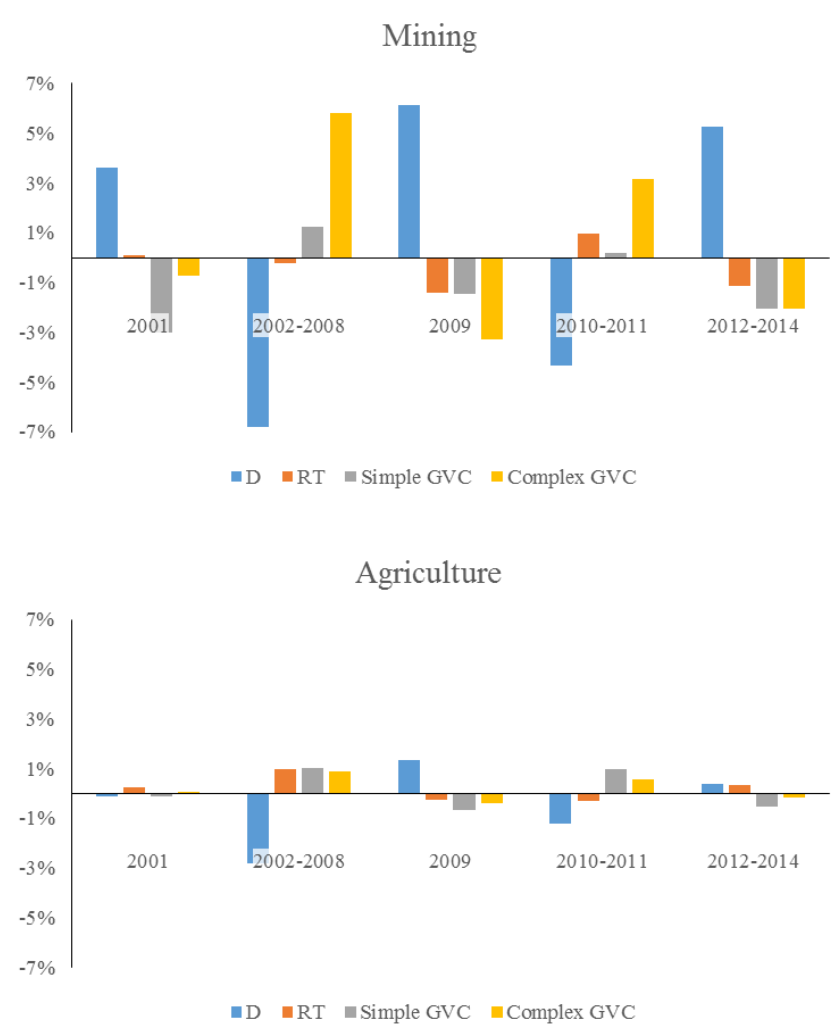

\subsection{Econometric Analysis}

The discussion in Section 4.1 suggests a possible link between the expansion and recession of aggregate economic activities and the share of GVC trade in total production activities. A number of recent papers have suggested that joining GVCs can bring 
positive and significant gains in productivity and technology spillover for the participating counties thus improving their economic growth (Baldwin and Yan, 2014; OECD 2014; IMF, 2015, World Bank 2016). This is because integration into GVCs reflects finer division of labor and task specialization, which enables firms to exploit finer niches consistent with their comparative advantage. However, none of these studies decomposes trade into traditional trade, and simple and complex GVC activities.

In this sub-section, we investigate the correlation between a country-sector's total value added growth and its participation in trade in general and GVC trade in particular. Given the data patterns in Figures 9 to 11, we consider four sub-periods: fast growth period (2002 to 2008), global financial crisis (2009), after-crisis recovery period (2010 and 2011) and the growth slow down period (2012-2014).

$$
\Delta \ln V A_{i c t}=\beta_{0}+\beta_{1} \times V \text {-Share }_{i c t}+\beta_{2} \times W_{c t}+\beta_{3} \times Z_{i t}+\gamma_{t}+\delta_{c}+u_{i c t}
$$

where

$\Delta \ln V A_{\text {ict }}$ equals to the change of sectoral GDP, $\ln \left(V A_{\text {ict }}\right)$ minus $\ln \left(V A_{\text {ict-1 }}\right)$, which quantifies the degree of economic growth (or recession) in industry $i$ of Country $c$;

$V$-Share ict $_{\text {is }}$ the share of different types of value added creation activities in sectoral GDP (D and RT shares, Simple and Complex GVC Participation indexes), which are derived from the industry level GDP decomposition based on forward-cross country, inter-industrial linkages;

$W_{c t}$ and $Z_{i t}$ represent country and sectoral level control variables, including GDP per capita, hours worked by high and medium-skilled workers (share in total hours), and capital intensity defined as share of capital return in value added.

We also control for the year and country fixed effects by including a year dummy $\gamma_{t}$ and a country dummy $\delta_{c}$ in the model. 
Table 6 Benchmark Regression Results

\begin{tabular}{|c|c|c|c|c|c|}
\hline \multirow{2}{*}{ Time Period } & \multicolumn{5}{|c|}{ Full Sample } \\
\hline & $\mathrm{D}$ & RT & GVC & Simple GVC & Complex GVC \\
\hline \multirow{2}{*}{ A. $2002-2008,2010-2011$} & $-0.0106^{* *}$ & -0.00967 & $0.0236 * * *$ & $0.0318 * *$ & $0.0678 * * *$ \\
\hline & $(0.00509)$ & $(0.0112)$ & $(0.00856)$ & $(0.0137)$ & $(0.0191)$ \\
\hline \multirow{2}{*}{ B. $2002-2008$} & -0.0136 & $-0.0191 *$ & $0.0382 * *$ & 0.0465 & $0.104 * * *$ \\
\hline & $(0.0104)$ & $(0.0112)$ & $(0.0156)$ & $(0.0301)$ & $(0.0262)$ \\
\hline \multirow{2}{*}{ C. $2010-2011$} & $-0.0120 * *$ & 0.0105 & $0.0202 * *$ & $0.0311 * *$ & $0.0543 * *$ \\
\hline & $(0.00550)$ & $(0.0190)$ & $(0.00824)$ & $(0.0129)$ & $(0.0211)$ \\
\hline \multirow{2}{*}{ D. 2009} & $0.232 * * *$ & $-0.175 * * *$ & $-0.309 * * *$ & $-0.439 * * *$ & $-0.720 * * *$ \\
\hline & $(0.0281)$ & $(0.0376)$ & $(0.0391)$ & $(0.0651)$ & $(0.0795)$ \\
\hline \multirow{2}{*}{ E. $2012-2014$} & -0.00625 & 0.0242 & 0.00610 & 0.0162 & 0.00626 \\
\hline & $(0.0119)$ & $(0.0263)$ & $(0.0169)$ & $(0.0335)$ & $(0.0315)$ \\
\hline \multirow{2}{*}{ Time Period } & \multicolumn{5}{|c|}{ Manufacturing Only } \\
\hline & $\mathrm{D}$ & $\mathrm{RT}$ & GVC & Simple GVC & Complex GVC \\
\hline \multirow{2}{*}{ A. $2002-2008,2010-2011$} & $-0.0127 * *$ & 0.00357 & $0.0219 * *$ & $0.0283^{*}$ & $0.0655 * * *$ \\
\hline & $(0.00589)$ & $(0.0118)$ & $(0.00926)$ & $(0.0148)$ & $(0.0214)$ \\
\hline \multirow{2}{*}{ B. $2002-2008$} & -0.0194 & -0.00180 & 0.0349 & 0.0372 & $0.0967 * * *$ \\
\hline & $(0.0154)$ & $(0.0132)$ & $(0.0225)$ & $(0.0457)$ & $(0.0338)$ \\
\hline \multirow{2}{*}{ C. $2010-2011$} & $-0.0125 * *$ & 0.0155 & $0.0201 * *$ & $0.0297 * *$ & $0.0570 * *$ \\
\hline & $(0.00561)$ & $(0.0190)$ & $(0.00832)$ & $(0.0125)$ & $(0.0227)$ \\
\hline \multirow{2}{*}{ D. 2009} & $0.222 * * *$ & -0.0581 & $-0.323 * * *$ & $-0.430 * * *$ & $-0.743 * * *$ \\
\hline & $(0.0394)$ & $(0.0457)$ & $(0.0526)$ & $(0.0837)$ & $(0.102)$ \\
\hline \multirow{2}{*}{ E. $2012-2014$} & -0.0113 & 0.0385 & 0.0126 & 0.0275 & 0.0208 \\
\hline & $(0.0144)$ & $(0.0333)$ & (0.0199) & $(0.0406)$ & $(0.0365)$ \\
\hline
\end{tabular}

Note: Only the coefficients of $V$-Share (D, RT, GVC, Simple GVC and Complex GVC) are reported in the table. Robust standard errors in parentheses. ${ }^{* * *} \mathrm{p}<0.01, * * \mathrm{p}<0.05, * \mathrm{p}<0.1$

The benchmark regression results are shown in Table 6. Each row represents a regression. For both the full sample and the manufacturing sector sub-sample, we see a positive association between GVC participation and economic growth (Period A, B and $\mathrm{C})$, and the estimated impact of complex GVC is larger and more significant than simple GVC. On the other hand, a larger share of pure domestic production activities (D) has a negative association with economic growth. In comparison, there is no clear link between the share of value-added in traditional trade and economic growth.

During the global financial crisis in the year 2009, all trade-related production activities, (both RT and GVC) were negatively affected. The higher the shares in GVC 
activities, especially the complex GVC activities, in total GDP, the greater the degree of such negative impact.

The relationship between economic growth and different types of production activities become weak and unclear after 2012.

When we include year and country fixed effects (Table 7), as well as other country and sectoral level control variables (Table 8) in our regression, the results still hold.

Table 7: Regression Results with Year and Country Fixed Effects

\begin{tabular}{|c|c|c|c|c|c|}
\hline \multirow{2}{*}{ Time Period } & \multicolumn{5}{|c|}{ Full Sample } \\
\hline & $\mathrm{D}$ & $\mathrm{RT}$ & GVC & Simple GVC & Complex GVC \\
\hline \multirow{2}{*}{ A. $2002-2008,2010-2011$} & $-0.0155 * * *$ & 0.00279 & $0.0274 * * *$ & $0.0393 * * *$ & $0.0744 * * *$ \\
\hline & $(0.00371)$ & $(0.0133)$ & $(0.00689)$ & $(0.00940)$ & $(0.0169)$ \\
\hline \multirow{2}{*}{ B. $2002-2008$} & $-0.0164 * *$ & -0.00989 & $0.0363 * * *$ & $0.0533 * * *$ & $0.0839 * * *$ \\
\hline & $(0.00694)$ & $(0.0107)$ & $(0.00841)$ & $(0.0141)$ & $(0.0185)$ \\
\hline \multirow{2}{*}{ C. $2010-2011$} & $-0.0208 * * *$ & $0.0392 * *$ & $0.0301 * * *$ & $0.0437 * * *$ & $0.0875 * * *$ \\
\hline & $(0.00667)$ & $(0.0168)$ & $(0.00970)$ & $(0.0126)$ & $(0.0295)$ \\
\hline \multirow{2}{*}{ D. 2009} & $0.186 * * *$ & $-0.0826^{* *}$ & $-0.253^{* * *}$ & $-0.337 * * *$ & $-0.614 * * *$ \\
\hline & $(0.0302)$ & $(0.0384)$ & $(0.0403)$ & $(0.0667)$ & $(0.0841)$ \\
\hline \multirow{2}{*}{ E. $2012-2014$} & -0.00652 & $0.0237 *$ & 0.00667 & 0.0153 & 0.00991 \\
\hline & $(0.00598)$ & $(0.0138)$ & $(0.00889)$ & $(0.0167)$ & $(0.0178)$ \\
\hline \multirow{2}{*}{ Time Period } & \multicolumn{5}{|c|}{ Manufacturing Only } \\
\hline & $\mathrm{D}$ & RT & GVC & Simple GVC & Complex GVC \\
\hline \multirow{2}{*}{ A. $2002-2008,2010-2011$} & $-0.0162 * * *$ & 0.0109 & $0.0244 * * *$ & $0.0339 * * *$ & $0.0695 * * *$ \\
\hline & $(0.00427)$ & $(0.0139)$ & $(0.00676)$ & $(0.00858)$ & \\
\hline \multirow{2}{*}{ B. $2002-2008$} & $-0.0335 * * *$ & 0.00630 & $0.0419 * * *$ & $0.0617 * * *$ & $0.0905 * * *$ \\
\hline & $(0.0118)$ & $(0.0135)$ & $(0.0117)$ & $(0.0203)$ & $(0.0236)$ \\
\hline \multirow{2}{*}{ C. $2010-2011$} & $-0.0138 * * *$ & 0.0221 & $0.0208 * * *$ & $0.0283 * * *$ & $0.0660 * *$ \\
\hline & $(0.00532)$ & $(0.0171)$ & $(0.00795)$ & $(0.00983)$ & $(0.0275)$ \\
\hline \multirow{2}{*}{ D. 2009} & $0.126^{* * *}$ & $0.0805^{*}$ & $-0.236^{* * *}$ & $-0.253^{* * *}$ & $-0.605^{* * *}$ \\
\hline & $(0.0454)$ & $(0.0458)$ & $(0.0558)$ & $(0.0883)$ & $(0.109)$ \\
\hline \multirow{2}{*}{ E. $2012-2014$} & $-0.0129 *$ & $0.0405^{* *}$ & $0.0151 *$ & $0.0307 *$ & 0.0278 \\
\hline & $(0.00665)$ & $(0.0171)$ & $(0.00915)$ & $(0.0174)$ & $(0.0183)$ \\
\hline
\end{tabular}

Note: $* * * \mathrm{p}<0.01, * * \mathrm{p}<0.05, * \mathrm{p}<0.1$. For time period A, B and C: Cluster standard errors (by country and sector) in parentheses. For time period D: Robust standard errors in parentheses, and only country fixed effects are included as there is only one year in the sample. 
Table 8 Regression Results with Other Control Variables

\begin{tabular}{|c|c|c|c|c|c|c|c|c|c|c|}
\hline & \multicolumn{5}{|c|}{ Full Sample } & \multicolumn{5}{|c|}{ Manufacturing Only } \\
\hline & (1) & (2) & (3) & (4) & (5) & (6) & (7) & (8) & (9) & (10) \\
\hline \multirow{2}{*}{$\mathrm{D}$} & $-0.0134 * * *$ & & & & & -0.0146 *** & & & & \\
\hline & $(0.00334)$ & & & & & $(0.00416)$ & & & & \\
\hline \multirow{2}{*}{$\mathrm{RT}$} & & $7.07 \mathrm{e}-05$ & & & & & 0.00962 & & & \\
\hline & & $(0.0120)$ & & & & & $(0.0123)$ & & & \\
\hline \multirow{2}{*}{ GVC } & & & $0.0248 * * *$ & & & & & $0.0221 * * *$ & & \\
\hline & & & $(0.00716)$ & & & & & $(0.00712)$ & & \\
\hline \multirow{2}{*}{ Simple GVC } & & & & $0.0335^{* * *}$ & & & & & $0.0301 * * *$ & \\
\hline & & & & $(0.00909)$ & & & & & $(0.00861)$ & \\
\hline \multirow{2}{*}{ Complex GVC } & & & & & $0.0718 * * *$ & & & & & $0.0643 * * *$ \\
\hline & & & & & $(0.0187)$ & & & & & $(0.0193)$ \\
\hline \multirow{2}{*}{ GDP per Capita } & 0.0488 & 0.0492 & 0.0492 & 0.0490 & 0.0496 & 0.0227 & 0.0225 & 0.0236 & 0.0234 & 0.0239 \\
\hline & $(0.0330)$ & $(0.0330)$ & $(0.0330)$ & $(0.0330)$ & $(0.0330)$ & $(0.0463)$ & $(0.0463)$ & $(0.0463)$ & $(0.0463)$ & $(0.0463)$ \\
\hline \multirow{2}{*}{ Capital Intensity } & $0.0133 * *$ & $0.0121 *$ & $0.0130 *$ & $0.0129 *$ & $0.0130 *$ & 0.00385 & 0.00545 & 0.00129 & 0.00173 & 0.00108 \\
\hline & $(0.00668)$ & $(0.00682)$ & $(0.00669)$ & $(0.00670)$ & $(0.00667)$ & $(0.0114)$ & $(0.0118)$ & $(0.0117)$ & $(0.0117)$ & $(0.0116)$ \\
\hline \multirow{2}{*}{ Skill } & $0.0309 * * *$ & $0.0298 * * *$ & $0.0313 * * *$ & $0.0311 * * *$ & $0.0315 * * *$ & 0.0340 & 0.0342 & $0.0412 *$ & $0.0428 *$ & 0.0372 \\
\hline & $(0.0113)$ & $(0.0112)$ & $(0.0113)$ & $(0.0112)$ & $(0.0113)$ & $(0.0252)$ & $(0.0254)$ & $(0.0249)$ & $(0.0249)$ & $(0.0249)$ \\
\hline \multirow{2}{*}{ Constant } & -0.420 & -0.433 & -0.438 & -0.436 & -0.442 & -0.163 & -0.173 & -0.190 & -0.188 & -0.191 \\
\hline & $(0.344)$ & $(0.343)$ & $(0.343)$ & $(0.343)$ & $(0.343)$ & $(0.482)$ & $(0.482)$ & $(0.482)$ & $(0.482)$ & $(0.482)$ \\
\hline Year Dummy & YES & YES & YES & YES & YES & YES & YES & YES & YES & YES \\
\hline Country Dummy & YES & YES & YES & YES & YES & YES & YES & YES & YES & YES \\
\hline Observations & 10,176 & 10,176 & 10,176 & 10,176 & 10,176 & 5,618 & 5,618 & 5,618 & 5,618 & 5,618 \\
\hline R-squared & 0.106 & 0.105 & 0.106 & 0.106 & 0.107 & 0.105 & 0.104 & 0.105 & 0.105 & 0.105 \\
\hline
\end{tabular}

Note: Cluster standard errors (by country and sector) in parentheses. ${ }^{* * *} \mathrm{p}<0.01, * * \mathrm{p}<0.05, * \mathrm{p}<0.1$ 
We also divide the sample into two country group sub-samples: advanced economies (Table 9a) and developing countries (Table 9b) ${ }^{6}$. We find that the association between GVC participation and economic growth is more pronounced in advanced economies.

Table 9a Advanced Economies

\begin{tabular}{|c|c|c|c|c|c|c|c|c|}
\hline & \multicolumn{4}{|c|}{ Full Sample } & \multicolumn{4}{|c|}{ Manufacturing Only } \\
\hline & (1) & (2) & (3) & (4) & (5) & (6) & (7) & (8) \\
\hline \multirow{2}{*}{ Simple GVC } & $0.0302 * *$ & $0.0498 * *$ & & & $0.0441 * *$ & $0.0437 *$ & & \\
\hline & $(0.0125)$ & $(0.0200)$ & & & $(0.0210)$ & $(0.0223)$ & & \\
\hline \multirow{2}{*}{ Complex GVC } & & & $0.0453 * * *$ & $0.0914 * * *$ & & & $0.0798 * * *$ & $0.0760 * * *$ \\
\hline & & & $(0.0158)$ & $(0.0230)$ & & & $(0.0200)$ & $(0.0246)$ \\
\hline \multirow{2}{*}{ GDP per Capita } & & $-0.0830 *$ & & -0.0811 & & $-0.133 *$ & & $-0.131 *$ \\
\hline & & $(0.0504)$ & & $(0.0503)$ & & $(0.0709)$ & & $(0.0708)$ \\
\hline \multirow{2}{*}{ Capital Intensity } & & -0.0106 & & -0.0106 & & $-0.0304 * *$ & & $-0.0299 * *$ \\
\hline & & $(0.00803)$ & & $(0.00802)$ & & $(0.0139)$ & & $(0.0134)$ \\
\hline \multirow{2}{*}{ Skill } & & $0.0577 * * *$ & & $0.0593 * * *$ & & 0.0168 & & 0.00839 \\
\hline & & $(0.0189)$ & & $(0.0191)$ & & $(0.0418)$ & & $(0.0415)$ \\
\hline \multirow{2}{*}{ Constant } & $0.117 * * *$ & $0.935^{*}$ & $0.118 * * *$ & $0.916^{*}$ & $0.0865 * * *$ & $1.468 * *$ & $0.0875 * * *$ & $1.454 * *$ \\
\hline & $(0.00514)$ & $(0.524)$ & $(0.00511)$ & $(0.523)$ & $(0.00724)$ & $(0.738)$ & $(0.00702)$ & $(0.738)$ \\
\hline Year Dummy & YES & YES & YES & YES & YES & YES & YES & YES \\
\hline Country Dummy & YES & YES & YES & YES & YES & YES & YES & YES \\
\hline Observations & 11,169 & 5,277 & 11,169 & 5,277 & 3,888 & 2,914 & 3,888 & 2,914 \\
\hline R-squared & 0.141 & 0.164 & 0.141 & 0.165 & 0.131 & 0.159 & 0.132 & 0.160 \\
\hline
\end{tabular}

\footnotetext{
${ }^{6}$ Following the classification used in Timmer et al.(2012), advanced (or mature) economies include Australia, Canada, Japan, South Korea, Taiwan, US, and the 15 countries that joined the EU before 2004. Developing countries (or emerging economies) include Brazil, China, Russia, India, Indonesia, Mexico and Turkey and the 12 countries that joined the EU in 2004.
} 
Table 9b Emerging Economies

\begin{tabular}{|c|c|c|c|c|c|c|c|c|}
\hline & \multicolumn{4}{|c|}{ Full Sample } & \multicolumn{4}{|c|}{ Manufacturing Only } \\
\hline & (1) & (2) & (3) & (4) & (5) & (6) & (7) & (8) \\
\hline \multirow{2}{*}{ Simple GVC } & $0.0331 * * *$ & $0.0291 * * *$ & & & $0.0321 * * *$ & $0.0279 * * *$ & & \\
\hline & $(0.00840)$ & $(0.00764)$ & & & $(0.00820)$ & $(0.00755)$ & & \\
\hline \multirow{2}{*}{ Complex GVC } & & & $0.0593 * * *$ & $0.0646 * * *$ & & & $0.0669 * * *$ & $0.0608 * * *$ \\
\hline & & & $(0.0150)$ & $(0.0191)$ & & & $(0.0190)$ & $(0.0200)$ \\
\hline \multirow{2}{*}{ GDP per Capita } & & 0.0408 & & 0.0422 & & -0.0123 & & -0.0107 \\
\hline & & $(0.0453)$ & & $(0.0453)$ & & $(0.0633)$ & & $(0.0633)$ \\
\hline \multirow{2}{*}{ Capital Intensity } & & $0.0413 * * *$ & & $0.0412 * * *$ & & $0.0400 * *$ & & $0.0389 * *$ \\
\hline & & $(0.0110)$ & & $(0.0110)$ & & $(0.0192)$ & & $(0.0191)$ \\
\hline \multirow{2}{*}{ Skill } & & 0.0159 & & 0.0157 & & $0.0633 * *$ & & $0.0583^{*}$ \\
\hline & & $(0.0136)$ & & $(0.0135)$ & & $(0.0314)$ & & $(0.0314)$ \\
\hline \multirow{2}{*}{ Constant } & $0.156 * * *$ & -0.265 & $0.156 * * *$ & -0.278 & $0.147 * * *$ & 0.208 & $0.146^{* * *}$ & 0.194 \\
\hline & $(0.0101)$ & $(0.411)$ & $(0.0101)$ & $(0.412)$ & $(0.0128)$ & $(0.575)$ & $(0.0128)$ & $(0.576)$ \\
\hline Year Dummy & YES & YES & YES & YES & YES & YES & YES & YES \\
\hline Country Dummy & YES & YES & YES & YES & YES & YES & YES & YES \\
\hline Observations & 9,271 & 4,899 & 9,271 & 4,899 & 3,306 & 2,704 & 3,306 & 2,704 \\
\hline R-squared & 0.072 & 0.059 & 0.072 & 0.060 & 0.065 & 0.058 & 0.066 & 0.059 \\
\hline
\end{tabular}

\section{Conclusion}

In this paper we propose a production activity accounting framework based on whether factor content crosses national borders for production or not. This allows one to decompose a country/sector's GDP and final goods production into pure domestic activities and GVC production activities. We show that a pair of GVC participation indices built on such framework have more desirable properties than the existing ones in the literature.

Applying our tools to the most up-to-date inter-country input-output database (WIOD, 2016), we show that complex GVC was the most important driving force for globalization and co-moves strongly with the growth of global GDP, both in booms and in recessions. Our work at this point only documents an association, investigating causal relations will be a fruitful future project. 


\section{Reference}

Baldwin, Richard, and Javier Lopez-Gonzalez. "Supply-Chain Trade: A Portrait of Global Patterns and Several Testable Hypotheses." NBER Working Paper 18957. National Bureau of Economic Research. Washington, DC, 2013

Hummels, David, Jun Ishii, and Kei-Mu Yi. "The Nature and Growth of Vertical Specialization in World Trade." Journal of International Economics 2001, 54:75-96.

Hummels D, Ishii J, Yi K M. The Nature and Growth of Vertical Specialization in World Trade. Journal of International Economics, 2001, 54(1): 75-96.

Johnson R C, Noguera G. Accounting for Intermediates: Production Sharing and Trade in Value Added. Journal of International Economics, 2012, 86(2): 224-236.

Koopman R B, Wang Z, Wei S J. Estimating Domestic Content in Exports When Processing Trade is Pervasive. Journal of Development Economics, 2012, 99(1): 178-189.

Koopman R B, Wang Z, Wei S J. Tracing Value-Added and Double Counting in Gross Exports. The American Economic Review, 2014, 104(2): 459-494.

Leontief, W. "Quantitative Input and Output Relations in the Economic System of the United States." Review of Economics and Statistics 1936, 18: 105-125.

Miller, R. E., and P. D. Blair. Input-output Analysis: Foundations and Extensions. Cambridge: Cambridge University Press. 2009

Miller R E, Temurshoev U, Output Upstreamness and Input Downstreamness of Industries/Countries in World Production. International Regional Science Review, November 5, 20150160017615608095

Timmer, M., A. A. Erumban, J. Francois, A. Genty, R. Gouma, B. Los, F. Neuwahl, O. Pindyuk, J. Poeschl, J.M. Rueda-Cantuche, R. Stehrer, G. Streicher, U. Temurshoev, A. Villanueva, G.J. de Vries. "The World Input-Output Database (WIOD): Contents, Sources and Methods." 2012. WIOD Background document available at www.wiod.org.

Timmer, M. P., Los, B., Stehrer, R. and de Vries, G. J. (2016), "An Anatomy of the Global Trade Slowdown based on the WIOD 2016 Release", GGDC research memorandum number 162. Wang Z, Wei S J, Zhu K. Quantifying International Production Sharing at the Bilateral and Sector Level. NBER Working Paper Series, 2013. 


\section{Appendix}

\section{Appendix A: Derivation of term 3 b in Equation (3)}

The term $3 b$ in equation (3) can be further divided into returned value added and foreign value added based on their final destinations of absorption.

$$
\begin{aligned}
& \widehat{V} L A^{F}\left(B \widehat{Y}-L \hat{Y}^{D}\right)=\widehat{V} L A^{F} B \widehat{Y}-\widehat{V} L A^{F} L \hat{Y}^{D} \\
& =\hat{V} L\left(A^{F} B\right)^{D} \hat{Y}+\hat{V} L\left(A^{F} B\right)^{F} \hat{Y}-\hat{V} L A^{F} L \hat{Y}^{D} \\
& =\widehat{V} L\left(A^{F} B\right)^{D} \hat{Y}+\widehat{V} L\left[\left(A^{F} B\right)^{F} \hat{Y}-A^{F} L \hat{Y}^{D}\right]
\end{aligned}
$$

Where $\left(A^{F} B\right)^{D}$ is a diagonal matrix of $A^{F} B$ with sub-matrics, and $\left(A^{F} B\right)^{F}$ is a off-diagonal matrix of $A^{F} B$ with sub-matrics. $\widehat{V} L\left(A^{F} B\right)^{D} \widehat{Y}$ is the returned value added embodied in intermediate exports and further returned home country for production of final goods and services, $\hat{V} L\left[\left(A^{F} B\right)^{F} \hat{Y}-A^{F} L \hat{Y}^{D}\right]$ is the value added embodied in intermediate exports that is used by partner country to produce exports of final products or intermediate inputs for other countries' production of final goods and services that are eventually re-exported and consumed abroad.

\section{Appendix B: Proof of Equations (5) and (6)}

As equation (2) in main text, the gross input production can be written as:

$$
\begin{aligned}
& X=\left(I-A^{D}\right)^{-1} Y^{D}+\left(I-A^{D}\right)^{-1} E=L Y^{D}+L E \\
& =L Y^{D}+L Y^{F}+L A^{F} B Y
\end{aligned}
$$

Pre-multiplying with the GN by GN direct value-added diagonal matrix $\widehat{V}$,

$$
\begin{aligned}
& V a^{\prime}=\hat{V} X=\hat{V} L Y^{D}+\hat{V} L Y^{F}+\widehat{V} L A^{F} B Y \\
& =\underbrace{\widehat{V} L Y^{\mathrm{D}}}_{(1)-V_{-} \mathrm{D}}+\underbrace{\widehat{V} L Y^{\mathrm{F}}}_{(2)-V_{-} \mathrm{RT}}+\underbrace{\widehat{V} L A^{\mathrm{F}} L Y^{\mathrm{D}}}_{(3 \mathrm{a})-V_{-} \mathrm{GVC} C_{-} S}+\underbrace{\widehat{V} L A^{\mathrm{F}}\left(\mathrm{BY}-\mathrm{LY}^{\mathrm{D}}\right)}_{(3 \mathrm{~b})-\mathrm{V}_{-} \mathrm{GVC} C_{-} \mathrm{C}}
\end{aligned}
$$

The gross input production and use balance, or the column balance condition of the ICIO table in Table 1 can be written as:

$$
u \hat{X}=u A \hat{X}+V \hat{X}
$$

Rearranging the equation (B1) yields

$$
u=V(I-A)^{-1}=V B
$$


Inserting the final products production as a diagonal matrix into equation (B4), the decomposition of final products production based on the Leontief model can be expressed as follows:

$$
Y^{\prime}=V B \hat{Y}
$$

Expanding equation (B5), final products production at each country/sector pair can be decomposed into five different parts as follows:

$$
Y^{\prime}=V B \hat{Y}=\underbrace{V L \hat{Y}^{D}}_{(1)-Y_{-} D}+\underbrace{V L \hat{Y}^{F}}_{(2)-Y_{-} R T}+\underbrace{V L A^{F} L \hat{Y}^{D}}_{(3 a)-Y_{-} G V C_{-} S}+\underbrace{V L A^{F}\left(B \hat{Y}-L \hat{Y}^{D}\right)}_{(3 b)-Y_{-} G V C_{-} C}
$$

\section{Appendix C: Two GVC participation indexes at global level, based on forward and backward industrial linkages, respectively}

As shown in Equations (6) and (7), the GVC participation indexes based on forward and backward industrial linkage can be defined as

$$
\begin{aligned}
& G V C_{-} P A T_{-} f=\frac{V_{-} G V C}{\widehat{V a}^{\prime}}=\frac{\widehat{V} L A^{F} B Y}{\widehat{V a}^{\prime}} \\
& G V C_{-} P A T_{-} b=\frac{Y_{-} G V C}{Y^{\prime}}=\frac{V B A^{F} L \widehat{Y \mu}}{Y^{\prime}}
\end{aligned}
$$

Aggregating to the world level

$$
\begin{aligned}
& G V C_{-} P A T_{-} f^{w}=\frac{u V_{-} G V C}{u \widehat{V a}}=\frac{u \widehat{V} L A^{F} B Y}{u G D P}=\frac{V L A^{F} B Y \mu}{u G D P}=1-\frac{V L Y}{u G D P} \\
& G V C_{-} P A T_{-} b^{w}=\frac{Y_{-} G V C u^{\prime}}{u Y}=\frac{V B A^{F} L Y}{u G D P}=1-\frac{V L Y \mu}{u G D P}
\end{aligned}
$$

Obviously, the numerators in equations (C3) and (C4) are the same. Therefore, GVC participation indexes based on forward and backward industrial linkage equal each other at the global level. 